\title{
Non-dimensional solutions for the stabilising piles in landslides in layered cohesive soils considering non-linear soil-pile interactions
}

\author{
GUOPING LEI*, DONG SU† and MIGUEL ANGEL CABRERA
}

\begin{abstract}
The pile response is of great importance to the effectiveness of a row of piles used as a landslide mitigation method. However, the current classifications of the pile responses and failure modes do not consider the effects of soil displacement and the relative pile rigidity. An attempt is made in this paper to improve this using a non-dimensional model based on simplified ground consisted of two layers of cohesive soils. A hyperbolic $p-y$ model is adopted to consider non-linear soil reactions. The calculations of three case histories show that the proposed model predicts the pile responses well. The dependencies for obtaining a pile response with maximum pile resistance have been identified and the influencing factors have been examined. The efficacy of the proposed approach has been demonstrated by the satisfactory result that it achieves in reproducing the more complex three-dimensional finite-element analyses. The application of the non-dimensional solutions indicates that it can increase the efficiency of the preliminary pile design.
\end{abstract}

KEYWORDS: clays; finite-element modelling; landslides; piles \& piling; soil stabilisation; soil/structure interaction

\section{INTRODUCTION}

Mass movements are catastrophic events which threaten both infrastructure and human lives. One of the main mitigation methods against these events is to install rows of piles, transferring the sliding force from the moving mass to the stable ground underneath. Each pile interacts with the adjacent piles, giving rise to an arching effect. The main factor influencing the soil arching effect is the axis-to-axis pile spacing. This factor has been studied by many research groups, using various approaches (Chen \& Martin, 2002; Liang \& Zeng, 2002; Durrani et al., 2008; Yoon \& Ellis, 2009; Ellis et al., 2010; Kourkoulis et al., 2011; Li et al., 2013). From these works, it is commonly concluded that the soil arching between adjacent piles can be maintained when the pile spacing is smaller than a limit value, often referred as about 4 times the pile diameter. With a larger pile spacing, the soil arching effect diminishes and the piles behave almost as single isolated elements. Such a limit value is of significant practical importance in design methods; it can be thought of as the most cost-effective arrangement (Kourkoulis et al., 2011). This study deals with the response calculation of a row of stabilising piles, including the pile deflection, internal forces and the profile of the pile-soil contact forces. As regards the pile spacing, the limit value is assumed

Manuscript received 29 July 2020; revised manuscript accepted 5 February 2021. Published online ahead of print 10 March 2021.

Discussion on this paper closes on 1 December 2022, for further details see p. ii.

Published with permission by the ICE under the CC-BY 4.0 license. (http://creativecommons.org/licenses/by/4.0/)

* College of Civil and Transportation Engineering, Shenzhen University, Shenzhen, Guangdong, P. R. China.

$\dagger$ College of Civil and Transportation Engineering, Shenzhen University, Shenzhen, Guangdong, P. R. China; also Key Laboratory of Coastal Urban Resilient Infrastructure (MOE), Shenzhen University, Shenzhen, Guangdong, P. R. China (corresponding author) (Orcid:0000-0002-6175-6827).

+ Department of Civil and Environmental Engineering, Universidad de los Andes, Bogotá, Colombia

(Orcid:0000-0002-9236-8130). and empirical results of the maximum pile resistance are adopted.

The pile response is of great importance to the effectiveness of the stabilisation method and the associated potential failure mode. By performing limit equilibrium analysis, Viggiani (1981) identified six possible failure mechanisms (mechanisms A, B, C for non-yielding piles and mechanisms B1, BY, B2 for yielding piles) depending on two parameters namely, the ratio of the embedded length to the pile length in the sliding layer $(\lambda)$ and the ratio of the soil lateral capacity between the sliding and stable layers $(\chi)$. As shown in Fig. 1 $(\chi=0.5)$, mode A refers to the case where the whole pile translates together with the sliding soil, which corresponds to the 'short pile mode' by Poulos (1995), meaning that the length of pile in the stable soil is relatively shallow and the yield value of the pile-soil interaction is only attained in the stable soil layer. This failure mode must be avoided because limited contribution to soil stability is expected (Di Laora et al., 2017). Mode C, also the 'flow mode' by Poulos (1995), occurs when the sliding layer is relatively shallow and embedment is sufficiently long. The unstable soil becomes plastic and flows around the pile, providing the maximum resistance from the pile for the slope. Mode B describes the cases between the above two extreme cases (also the 'intermediate mode' by Poulos (1995)), in which soil failure occurs both above and below the slip surface. As the one most likely to be associated with a plastic hinge, mode $\mathrm{B}$ could become mode $\mathrm{B} 1, \mathrm{BY}$ or $\mathrm{B} 2$ depending on where the yielding moment of the pile cross-section is first attained.

Figure 1 also depicts that the pile resistance becomes much lower for modes A and B (especially B1 and BY). As a result, slopes reinforced by piles with these pile responses have lower overall stability (Lei \& Wu, 2020). With the perspective of resisting soil movement, mode $\mathrm{C}$ is preferred, in which the ultimate pile-soil contact pressure in the sliding soil can be applied to the pile as an equivalent loading condition (Ito \& Matsui, 1975). In this regard, the framework presented by Viggiani (1981) is convenient in predicting the pile response; however, the inherent drawbacks of the pressurebased methods based on limit equilibrium analyses remain. 


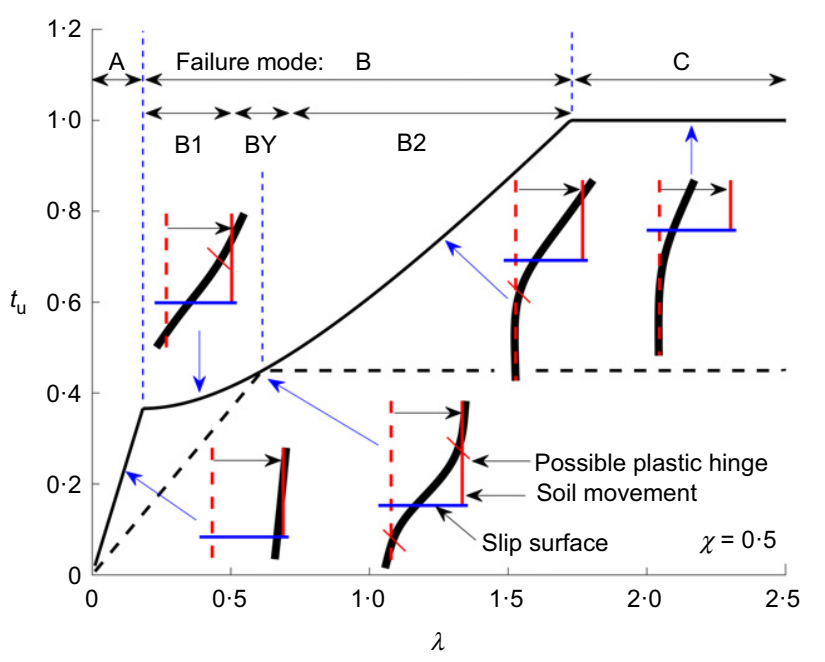

Fig. 1. Illustration of different failure modes identified by Viggiani (1981)

The evolution of the pile response with soil movement and the pile rigidity is not considered (Kanagasabai et al., 2011). As a result, these methods are often not satisfied for free-headed, slender piles (White et al., 2008). To incorporate lateral soil displacements and the pile rigidity into pile response analyses, more sophisticated displacement-based methods are necessary (Poulos, 1973; Byrne et al., 1984; Cai \& Ugai, 2003).

A dimensionless pile length $\beta L$ is often used to determine whether a laterally loaded pile, equivalent to the embedded part of the stabilising pile, behaves rigidly or flexibly (Broms 1964; Poulos 1971; Randolph 1981), where $L$ is the length of the laterally loaded pile, the coefficient $\beta=\sqrt[4]{k_{\mathrm{h}} /(4 E I)}$, where $k_{\mathrm{h}}$ is the coefficient of subgrade reaction, $E$ is the pile's Young's modulus and $I$ is the second moment of inertia for the pile's cross-section. Based on a subgrade reaction method with the assumption of linear soil reaction, Cai \& Ugai (2003, 2011) have studied the influence of the soil displacement profile on the pile response for flexible and rigid pile segments in the sliding region. In their studies, a dimensionless length $\beta L_{1}>3$ is adopted to identify a flexible pile segment (mode BY), where $L_{1}$ is the pile length in the sliding soil. Based on an equivalent load transfer approach, Guo (2013) has developed elastic (sliding layer)-elastic (stable layer) (E-E) solutions, and plastic (sliding layer)elastic-plastic (stable layer) (P-EP) solutions for the analyses of deep (mode BY) and normal sliding modes (modes B2 and C), respectively. The pile response is calculated by the former solutions when the pile segment in the sliding soil is longer than $1 \cdot 2 L_{\mathrm{c} 1}+x_{\mathrm{p} 1}$, where $L_{\mathrm{c} 1}$ is the critical length of an active long pile in the sliding soil and $x_{\mathrm{p} 1}$ is the thickness of the plastic zone in the sliding soil. The classifications adopted by Cai \& Ugai $(2003,2011)$ and Guo (2013) provide the scope of application of the simplified calculation methods for long flexible piles, which can also be seen as an exploration of the boundary between modes B2 and BY.

Alternative studies on the responses of stabilising piles employ numerical simulations (Martin \& Chen, 2005; Kanagasabai et al., 2011; Kourkoulis et al., 2011), physical models (Guo \& Qin, 2010; Lei \& Wu, 2020; White et al., 2008; Tang et al., 2014; Li et al., 2016a) and simplified methods (Chow, 1996; Chen \& Poulos, 1997), without exploring the boundaries among the failure modes. The stabilisation of a failing slope requires the maximum resistance from the piles, thus identifying the boundary between modes B and C appears to be more useful. This is achieved by developing a non-dimensional formulation of the subgrade reaction method proposed by $\mathrm{Su}$ et al. (2018) for the analysis of stabilising piles incorporating a hyperbolic $p-y$ model, where $p$ is the soil-pile contacting pressure and $y$ is the absolute difference between the pile displacement $y_{\mathrm{p}}$ and the soil displacement $y_{\mathrm{s}}$. Advanced three-dimensional (3D) numerical methods reveal clearly the characteristics of different pile responses (Kanagasabai et al., 2011). The main drawback of such an approach lies in the significant dependency on the model geometry and material properties, which usually demands a large amount of modelling effort for design optimisation. The proposed approach, like other accepted macroscopic methods (Byrne et al., 2020; Z. Salciarini \& Tamagnini, 2009; Li et al., 2016b; Page et al., 2018), overcomes the above drawback and is also able to deliver results with comparative accuracy by providing well-calibrated parameters using representative testing and simulation data.

The objectives of this study are: $(a)$ to reveal the evolution of pile response with the sliding soil displacement and the relative pile stiffness, and explore the boundary between mode $\mathrm{B}$ and $\mathrm{C}$; $(b)$ to demonstrate the efficacy of the proposed approach by the satisfactory result that it achieves in reproducing the more complex 3D finite-element analyses; and $(c)$ to show the ability of the proposed method to facilitate the design of piles as a mitigation structure.

\section{NON-DIMENSIONAL MODEL FOR STABILISING PILES}

Similarly to previous theoretical studies of stabilising piles (Poulos, 1995; Chow, 1996; Cai \& Ugai, 2003, 2011), the non-dimensional analysis is based on an idealised ground model. In this section, the idealised ground model for landslides in cohesive soils is introduced. Subsequently, the hyperbolic $p-y$ model and the normalisation method are described. Finally, the $p-y$ model is verified through three reported practical cases.

\section{Idealised ground model for landslides in cohesive soils}

For the topic of pile-soil interaction, the accuracy of the analysis depends greatly on the $p-y$ curves, which ideally should be obtained by way of in situ tests. However, measured soil reactions are not always available. In this paper, the authors focus on the case where the landslide occurs in cohesive soils with a constant soil strength profile. Modification should be made when using the proposed approach for the case where the soil strength varies erratically with depth. The geometry of the pile and soil layers is shown in Fig. 2. The soil slides along a slip surface at a depth $L_{1}$,

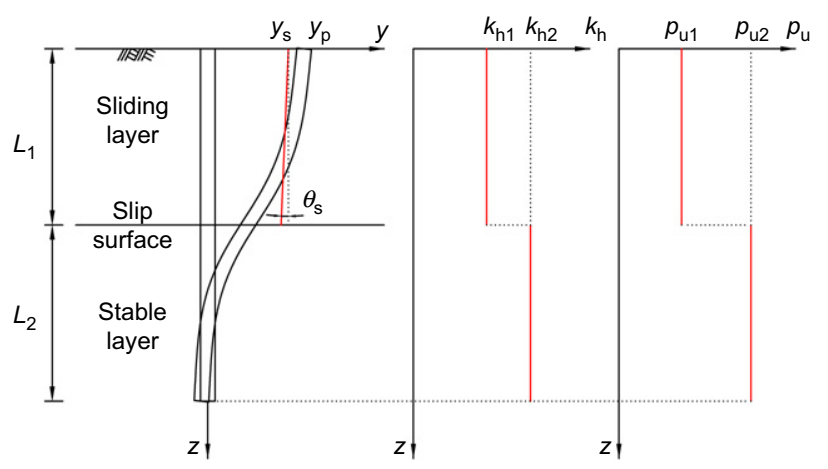

Fig. 2. Diagram of the model geometry, the simplified soil movement $y_{\mathrm{s}}$ and the depth profiles of $k_{\mathrm{h}}$ and $p_{\mathrm{u}}$ 
dividing the stabilising pile into a passive loading segment $\left(L_{1}\right)$ and an active loading segment $\left(L_{2}\right)$.

In the current analysis two parameters related to the soil reactions are needed: the horizontal subgrade reaction modulus $k_{\mathrm{h}}$ and the ultimate pile-soil contacting pressure $p_{\mathrm{u}} \cdot k_{\mathrm{h}}$ depends not only on the soil elastic modulus $E_{\mathrm{s}}$, but also on the relative stiffness of the soil-structure interaction system (Zhang \& Ahmari, 2013). Many $k_{\mathrm{h}}-E_{\mathrm{s}}$ relations have been proposed by previous studies of laterally loaded piles. As summarised by Zhang \& Ahmari (2013), $k_{\mathrm{h}} / E_{\mathrm{s}}$ ranges from 0.48 to 2 . The intention in this paper is to study the pilesoil interaction in a non-dimensional scale as a function of the ratio of $k_{\mathrm{h}}$ between the sliding soil and the stable soil. When the value of $k_{\mathrm{h}}$ is needed in the analysis, the aforementioned range of $k_{\mathrm{h}} / E_{\mathrm{s}}$ can be used. The sensitivity of $k_{\mathrm{h}}$ will also be investigated in this paper. $E_{\mathrm{s}}$ is commonly determined from the undrained shear strength, $c_{\mathrm{u}}$. Poulos (1995) suggested that $E_{\mathrm{s}} / c_{\mathrm{u}}$ lies between 150 and 400 . Table 1 lists the values of $E_{\mathrm{s}}$ at different values of $c_{\mathrm{u}}$ given in Zhang \& Ahmari (2013). It is postulated that $E_{\mathrm{s}} / c_{\mathrm{u}}$ and the $k_{\mathrm{h}}-E_{\mathrm{s}}$ relation does not vary with depth in each region; therefore, $k_{\mathrm{h}}$ is also assumed constant, as shown in Fig. 2.

The ultimate soil-pile contact pressure $p_{\mathrm{u}}$ in clay is related to the undrained shear strength $c_{\mathrm{u}}$ as follows

$$
P_{\mathrm{u}}=N_{\mathrm{p}} c_{\mathrm{u}}
$$

where $N_{\mathrm{p}}$ is the limit yield pressure coefficient. Viggiani (1981) suggested that, for the sliding soil above the slip surface, $N_{\mathrm{p}}=[3: 4]$, and for the stable soil below the slip surface, $N_{\mathrm{p}}=[8: 12]$. The lower value of $N_{\mathrm{p}}$ in the sliding zone is due to its proximity to the ground surface and the weakening of the soil due to the sliding movements (Chow, 1996). However, Poulos (1995) believes that $N_{\mathrm{p}}$ should be similar for both the sliding and stable layers, except the near-surface part. Although the numerical simulation performed in this paper, similarly to previous simulations (Kanagasabai et al., 2011), supports the opinion of Poulos (1995), this topic is not further explored. Apart from that, a group effect such as the arching effect also influences the ultimate soil capacity (Chen \& Poulos, 1997; Pan et al., 2002); however, it can be considered in the calibration process. Assuming that $N_{\mathrm{p}}$ does not vary with depth, the distribution of $p_{\mathrm{u}}$ is also constant as plotted in Fig. 2.

Normalisation of the pile flexural equation and the $\mathrm{p}-\mathrm{y}$ model

The proposed model is a non-dimensional version of the subgrade reaction method ( $\mathrm{Su}$ et al., 2018). The governing equation for the deflection of a pile facing lateral soil movement is expressed as

$$
E I \frac{\mathrm{d}^{4} y_{\mathrm{p}}}{\mathrm{d} z^{4}}+p=0
$$

where $z$ is the depth measured from the surface.

The hyperbolic function (Kondner, 1963) is commonly used to describe non-linear soil behaviour. Making use of the

Table 1. Clay elastic modulus based on its undrained shear strength (Zhang \& Ahmari, 2013)

\begin{tabular}{l|c|c}
\hline $\begin{array}{l}\text { Clay } \\
\text { consistency }\end{array}$ & $\begin{array}{c}\text { Undrained shear } \\
\text { strength, } c_{\mathrm{u}}: \mathrm{kPa}\end{array}$ & $\begin{array}{c}\text { Elastic modulus, } \\
E_{\mathrm{s}}: \mathrm{MPa}\end{array}$ \\
\hline Very soft clay & $2-25$ & $0 \cdot 5-5$ \\
Soft clay & $25-50$ & $5-20$ \\
Medium & $50-100$ & $20-50$ \\
Stiff & $100-200$ & $50-100$ \\
\hline
\end{tabular}

initial horizontal soil subgrade reaction modulus $k_{\mathrm{h}}$ and the ultimate pile-soil contacting pressure $p_{\mathrm{u}}$, the hyperbolic $p-y$ model takes the following form

$$
p=\frac{y}{\left(1 / k_{\mathrm{h}}\right)+\left(y / p_{\mathrm{u}}\right)}
$$

According to the normalisation method (Su et al., 2018), the reference displacement $y_{\mathrm{r}}$, the normalised displacement difference $y_{\mathrm{n}}$, the normalised soil resistance $p_{\mathrm{n}}$, the relative stiffness factor $T$ (Reese \& Van Impe, 2011) and the normalised depth $z_{\mathrm{n}}$ are defined as follows

$$
\begin{aligned}
& y_{\mathrm{r}}=\frac{p_{\mathrm{u}} D}{k_{\mathrm{h}}} \\
& y_{\mathrm{n}}=y_{\mathrm{pn}}-y_{\mathrm{sn}}=\frac{y_{\mathrm{p}}}{y_{\mathrm{r}}}-\frac{y_{\mathrm{s}}}{y_{\mathrm{r}}}=\frac{y}{y_{\mathrm{r}}} \\
& p_{\mathrm{n}}=\frac{p}{p_{\mathrm{u}}} \\
& T=\left(\frac{E I}{k_{\mathrm{h}}}\right)^{1 / 4} \\
& z_{\mathrm{n}}=\frac{z}{T}
\end{aligned}
$$

where $D$ is the pile diameter; $y_{\mathrm{pn}}$ and $y_{\mathrm{sn}}$ are the normalised pile and soil displacements, respectively. Substituting equations (4)-(6) into equation (3) yields

$$
p_{\mathrm{n}}=\frac{y_{\mathrm{n}}}{1+y_{\mathrm{n}}}
$$

Equation (9) is plotted in Fig. 3 together with the $p-y$ model for the soft clay suggested by the American Petroleum Institute (API, 2000). Note that the displacement at which the pile-soil contact pressure reaches $50 \%$ of the ultimate value $\left(y_{50}\right)$ coincides in both models, since $p_{\mathrm{n}}=0.5$ when $y_{\mathrm{n}}=1$ (i.e. $y=y_{\mathrm{r}}$ ). Both $p-y$ curves agree well in the range of $y_{\mathrm{n}}$ between 0 and 5 . When $y_{\mathrm{n}}$ is larger than 5, the API model increases rapidly, reaching a maximum, while the hyperbolic model approaches the line $p_{\mathrm{n}}=1$ slowly. The difference between the two models is less than 5\% when $y_{\mathrm{n}}$ is larger than $\sim 20$, which is the displacement range considered in this study. Note that it is always possible to use

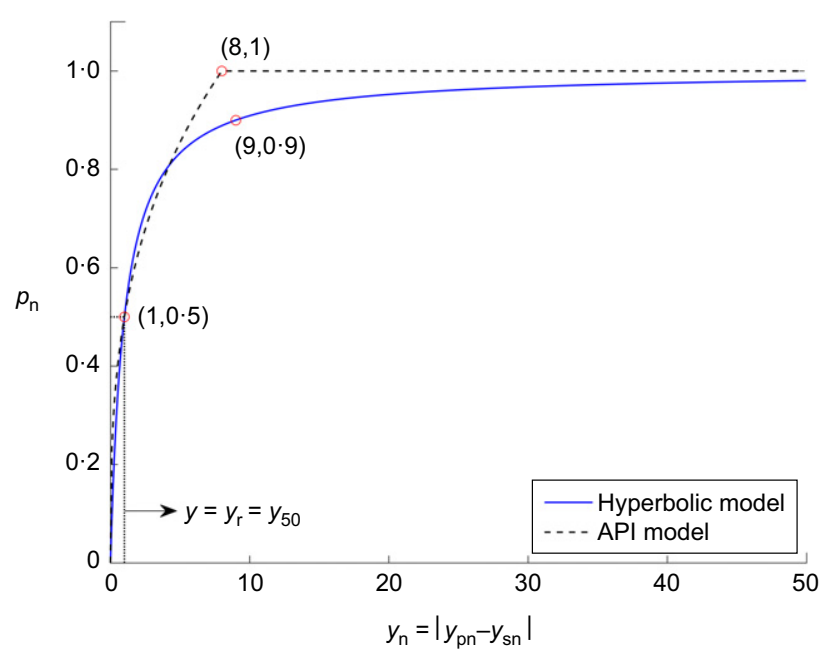

Fig. 3. Non-dimensional $p-y$ relationships 
a more complex model in the description of the soil behaviour. For instance, the H-model proposed by $\mathrm{Su}$ et al. (2018), which needs an additional model parameter, can be used to study the influence of soil non-linearity. For the purpose of this study, the simplicity of the hyperbolic model is appreciated.

When piles are used as a landslide stabilisation method, the soil-pile interaction in the sliding region is of most interest. Therefore, the sliding soil is taken as the reference for the normalisation in equations (4)-(8). For the stable layer, two parameters are introduced

$$
\begin{aligned}
& R_{k}=\frac{k_{\mathrm{h} 1}}{k_{\mathrm{h} 2}} \\
& R_{p}=\frac{p_{\mathrm{u} 1}}{p_{\mathrm{u} 2}}
\end{aligned}
$$

where subscripts 1 and 2 denote the parameter for the sliding and stable soil layers, respectively. Note that $R_{p}$ is equivalent to $\chi$ in Viggiani (1981). The normalised $p-y$ model for the pile segment in the stable layer is given by

$$
p_{\mathrm{n}}=\frac{y_{\mathrm{n}}}{R_{k}+R_{p} y_{\mathrm{n}}}
$$

Table 2. Conversions from the non-dimensional solution to the prototype scale

\begin{tabular}{l|l}
\hline Parameters & Conversion formulas \\
\hline Pile displacement & $\begin{array}{l}y_{\mathrm{p}}=y_{\mathrm{pn}} y_{\mathrm{r}} \\
y_{\mathrm{s}}=y_{\mathrm{sn}} y_{\mathrm{r}} \\
\text { Soil displacement }\end{array}$ \\
$\begin{array}{l}\text { Depth } \\
\text { Pile length }\end{array}$ & $\begin{array}{l}\mathrm{p}=L_{\mathrm{n}} T \\
\text { Soil resistance }\end{array}$ \\
Rotation of pile cross-section & $\theta=\frac{y_{\mathrm{r}}}{T} \theta_{\mathrm{n}}$ \\
Angle of soil displacement profile & $\theta_{\mathrm{s}}=\frac{y_{\mathrm{r}}}{T} \theta_{\mathrm{sn}}$ \\
Bending moment & $M=\frac{E I y_{\mathrm{r}}}{T^{2}} M_{\mathrm{n}}$ \\
Shear force & $F=\frac{E I y_{\mathrm{r}}}{T^{3}} F_{\mathrm{n}}$ \\
\hline
\end{tabular}

Substituting equations (4)-(8) into equation (2) results in the normalised pile flexural equation

$$
\frac{\mathrm{d}^{4} y_{\mathrm{pn}}}{\mathrm{d} z_{\mathrm{n}}^{4}}+p_{\mathrm{n}}=0
$$

To solve the pile response numerically, equations (9), (12) and (13) can be rewritten in incremental form as

$$
\begin{aligned}
& \Delta p_{\mathrm{n}}=\frac{\Delta y_{\mathrm{n}}}{\left(1+y_{\mathrm{n}}\right)^{2}} \\
& \Delta p_{\mathrm{n}}=\frac{R_{k} \Delta y_{\mathrm{n}}}{\left(R_{k}+R_{p} y_{\mathrm{n}}\right)^{2}} \\
& \frac{\mathrm{d}^{4} \Delta y_{\mathrm{pn}}}{\mathrm{d} z_{\mathrm{n}}^{4}}+\Delta p_{\mathrm{n}}=0
\end{aligned}
$$

A finite-difference code is developed for solving equations (14)-(16). The soil displacement profile in the sliding region can be obtained through filed measurements. When not available, a constant profile or a linear distribution with angle $\theta_{\mathrm{s}}$ (see Fig. 2) can be adopted (Cai \& Ugai, 2003). The non-dimensional solution can be scaled into a prototype through the equations listed in Table 2.

\section{Model verification and pile response characteristics}

Three reported case studies are used to validate the use of the hyperbolic $p-y$ relationship (Esu \& D'Elia, 1974; Carrubba et al., 1989; Kalteziotis et al., 1993). The parameters of these cases are summarised in Table 3. The main difference from previous analyses lies in the selection of the $k_{\mathrm{h}} / E_{\mathrm{s}}$ value. Ideally, $k_{\mathrm{h}}$ should be determined using the measured $p-y$ curves by way of equation (4), as $y_{\mathrm{r}}$ corresponds to the relative pile-soil displacement at $p=0 \cdot 5 p_{\mathrm{u}}$. In the case of Esu \& D'Elia (1974), $k_{\mathrm{h}} / E_{\mathrm{s}}$ is set to 2 while the value of 1 is adopted by Chow (1996). Note that $k_{\mathrm{h}}$ may vary in different methods. In the approach of Chow (1996), $k_{\mathrm{h}}$ is the gradient of the linear soil reaction

\begin{tabular}{|c|c|c|c|c|c|c|}
\hline \multirow{2}{*}{$\begin{array}{l}\text { Case history } \\
\text { Soil region }\end{array}$} & \multicolumn{2}{|c|}{ Esu \& D’Elia (1974) } & \multicolumn{2}{|c|}{ Carrubba et al. (1989) } & \multicolumn{2}{|c|}{ Kalteziotis et al. (1993) } \\
\hline & Sliding & Stable & Sliding & Stable & Sliding & Stable \\
\hline$L_{1}$ or $L_{2}: \mathrm{m}$ & $7 \cdot 5$ & $22 \cdot 5$ & $9 \cdot 5$ & $12 \cdot 5$ & $3 \cdot 64 *$ & $8 \cdot 36$ \\
\hline$c_{\mathrm{u}}: \mathrm{kPa}$ & 40 & 40 & 30 & 30 & 100 & 356 \\
\hline$E_{\mathrm{s}} / c_{\mathrm{u}}$ & 200 & 200 & 500 & 500 & 150 & 197 \\
\hline$k_{\mathrm{h}} / E_{\mathrm{s}}$ & $2 \dagger$ & $2 \dagger$ & $2 \ddagger$ & $2+$ & $0 \cdot 22^{\S}$ & 1 \\
\hline$p_{\mathrm{u}} / c_{\mathrm{u}}$ & & 8 & $3 \cdot 05$ & $5 \cdot 6$ & 3 & 8 \\
\hline$y_{\mathrm{s}}: \mathrm{mm}$ & 110 (uniform) & - & 95 (uniform) & - & Measured & - \\
\hline$L_{1}+L_{2}: \mathrm{m}$ & & 30 & 22 & 22 & 12 & 12 \\
\hline$D: \mathrm{m}$ & $0 \cdot 79$ & $0 \cdot 79$ & $1 \cdot 2$ & $1 \cdot 2$ & 1 & 1 \\
\hline$E I: \mathrm{MN} \mathrm{m}^{2}$ & 360 & 360 & $2035 \cdot 8$ & $2035 \cdot 8$ & 1540 & 1540 \\
\hline $\mathrm{T}: \mathrm{m}$ & $2 \cdot 18$ & $2 \cdot 18$ & $2 \cdot 87$ & $2 \cdot 87$ & $4 \cdot 65$ & $4 \cdot 65$ \\
\hline$L_{\mathrm{n} 1}$ or $L_{\mathrm{n} 2}$ & $3 \cdot 44$ & $10 \cdot 33$ & $3 \cdot 31$ & $4 \cdot 36$ & 0.79 & 1.79 \\
\hline & 1 & & 1 & 1 & $0 \cdot 047$ & $0 \cdot 047$ \\
\hline$R_{p}$ & $0 \cdot 375$ & $0 \cdot 375$ & $0 \cdot 545$ & $0 \cdot 545$ & $0 \cdot 105$ & $0 \cdot 015$ \\
\hline
\end{tabular}
before the ultimate value; therefore, the secant modulus of the soil reaction curve $\left(k_{\mathrm{sec}}\right)$ should be used. If $y_{50}\left(\right.$ or $\left.y_{\mathrm{r}}\right)$ is used to govern the soil reaction, $k_{\mathrm{sec}}$ is $50 \%$ of the initial tangent modulus in the hyperbolic model. $k_{\mathrm{h}} / E_{\mathrm{s}}=2$ is also given to the case of Carrubba et al. (1989). Special attention

Table 3. Parameters of the case histories

* Determined by comparing the measured pile and soil displacements.

$\dagger$ The value 1 is adopted in Chow (1996). It is adjusted to 2 for the hyperbolic model.

$\$$ Not given in Chen \& Poulos (1997). It is set to 2 for the hyperbolic model.

§The value 1 is adopted by Chow (1996), in which the influence of adjacent piles due to close pile spacing is intrinsically considered in the calculation. It is adjusted to $0 \cdot 22$ for the hyperbolic model. 
is paid in the case of Kalteziotis et al. (1993), where two rows of piles with a spacing-to-diameter ratio of 2.5 were installed, which, according to the analysis of Chow (1996), largely reduces the pile deflection and internal forces. Therefore, $k_{\mathrm{h} 1} / E_{\mathrm{s}}$ is set to $0 \cdot 22$ to consider this effect and match the measured pile displacement. Fig. 4 shows that the computed
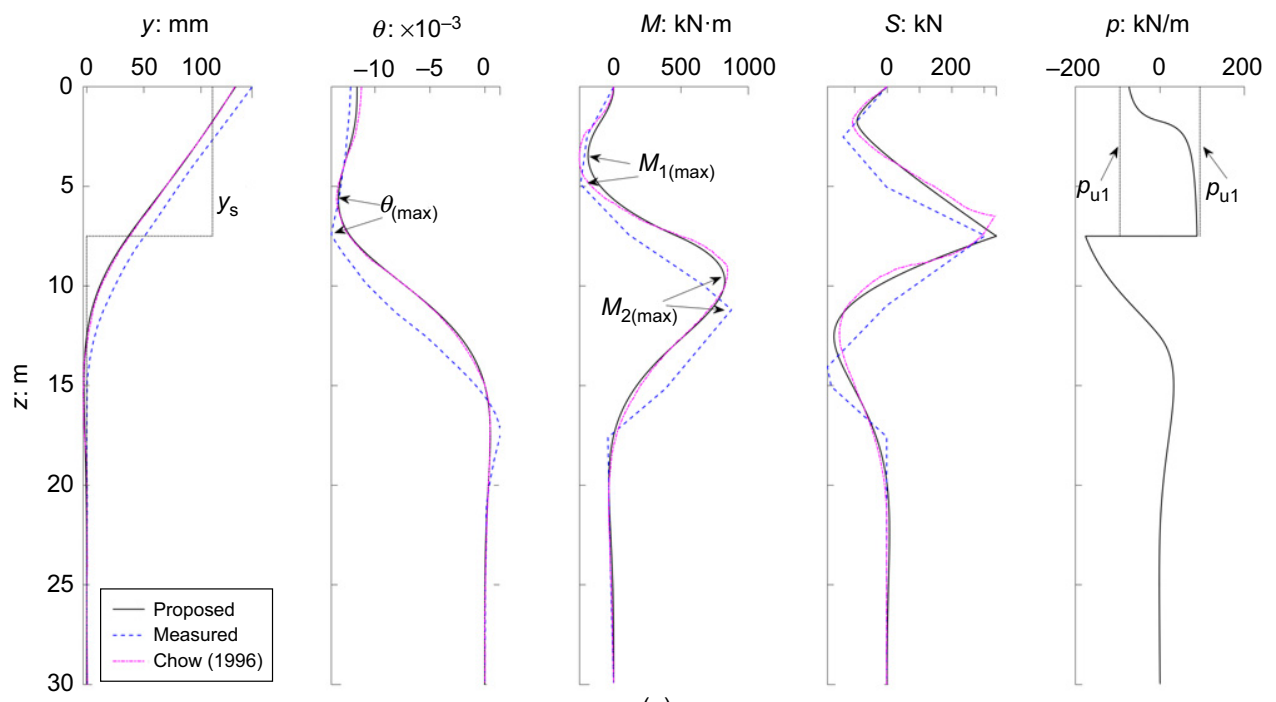

(a)
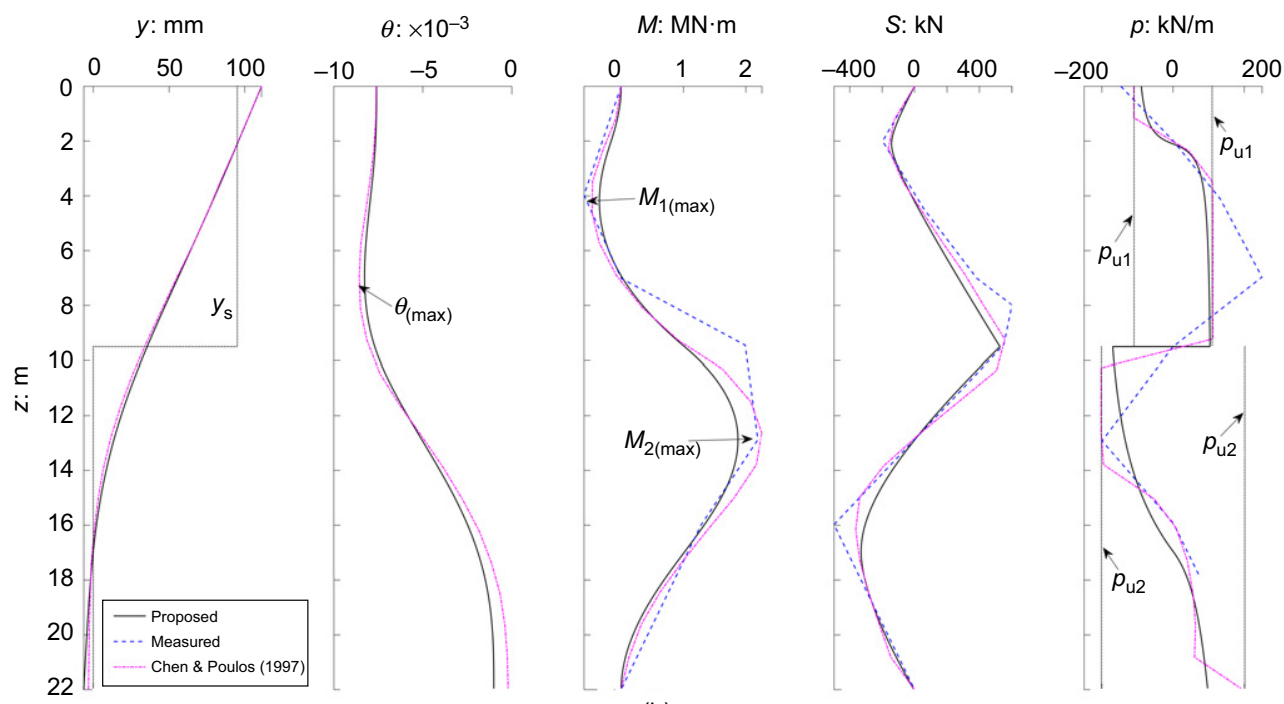

(b)
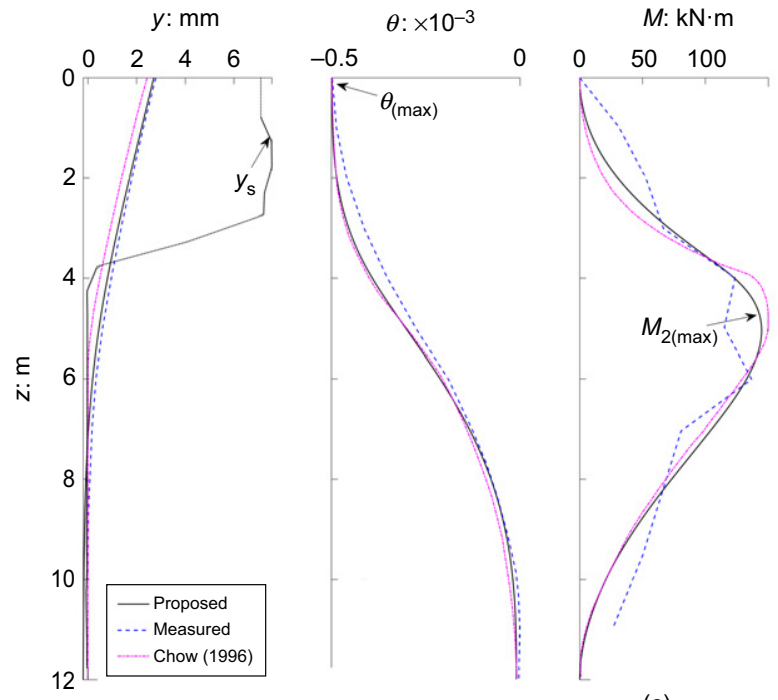

S: kN

$p: \mathrm{kN} / \mathrm{m}$
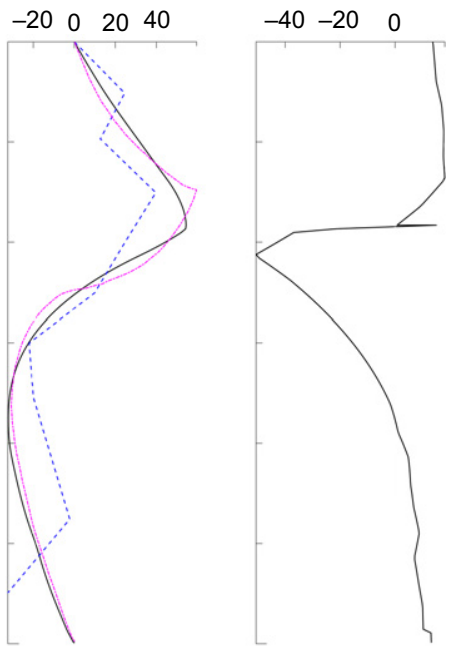

(c)

Fig. 4. Comparisons of the calculated results and field measurements: (a) Esu \& D'Elia (1974); (b) Carrubba et al. (1989); (c) Kalteziotis et al. (1993) 
pile deflection and internal forces match generally well with field measurements and previous analyses. Note that the purpose of the case studies is to verify that the simplified ground model and hyperbolic $p-y$ model can reproduce the previous observations with sufficient precision. However, in this study the authors do not intend to compare the accuracies of various methods, which may need the bending moment and shear force profiles for each magnitude of soil movement (Guo, 2013).

Some major characteristics of the pile responses are also observed from both the computed and measured data. Figs 4(a) and 4(b) present a typical mode B pile response, while Fig. 4(c) shows a typical mode $\mathrm{C}$ response. In the mode $\mathrm{B}$ case, the relative pile-soil displacement is significantly larger in the bottom section of the sliding soil than in the upper part. Therefore, the ultimate pile-soil contact pressure is first reached in this section. Moreover, the pile head displacement is larger than the soil displacement, resulting in negative soil pressures in the pile top section. Also, a negative bending moment $\left(M_{1}\right)$ exists from the ground surface to a certain depth below, and the pile cross-sectional rotation is smaller at the pile head than at the slip surface. In the mode $\mathrm{C}$ case, by contrast, the soil displacement is much larger than the pile displacement in the whole sliding layer. Neither negative bending moment nor negative pile-soil contacting pressure is observed above the slip surface; and the maximum rotation of the pile cross-section above the slip surface is located at the pile top. Note that in the mode B case, the magnitude of the negative bending moment in the sliding region becomes close to the maximum value in the stable region (mode BY) when the pile becomes relatively more flexible. As discussed earlier, the determination of the pile response case is of great importance in the pile design method. The mode $\mathrm{C}$ case creates the least damaging effect of soil movement on the pile and provides the largest resistance for slope stabilisation. However, the mode BY case makes the most use of the pile by generating large bending moments in both sliding and stable layers, which is preferred from the perspective of economy.

\section{FAILURE MODES IDENTIFICATION}

As pointed out previously, the identification of the failure modes by Viggiani (1981) does not incorporate the effect of soil displacement $\left(y_{\mathrm{sn}}\right)$ and relative pile-soil stiffness $\left(L_{\mathrm{n} 1}\right)$. In this section, this is improved by using the proposed non-dimensional formulations.

\section{Failure mode evolution with $\mathrm{y}_{s n}$ and $\mathrm{L}_{n l}$}

The pile response depends primarily on the normalised pile length (Broms, 1964), which corresponds to $L_{\mathrm{n} 1}$ in this study. The calculation of $L_{\mathrm{n} 1}$ is similar to those proposed previously by Broms (1964), Poulos (1971) and Randolph (1981). Previous studies characterise the pile response by the use of some critical values of $L_{\mathrm{n} 1}$, which usually does not take into account the influence of soil non-linearity. However, the study of $\mathrm{Su}$ et al. (2018), which incorporates non-linear soil-pile interaction, shows that the critical $L_{\mathrm{n} 1}$ for a long pile increases significantly with pile head displacement. Therefore, the study of the effect of $L_{\mathrm{n} 1}$ should be based on the possible free-field soil displacements.

To reveal the evolution of failure modes with $y_{\mathrm{sn}}$ and $L_{\mathrm{n} 1}$, the influence of the soil properties should be excluded. For this purpose, $R_{\mathrm{k}}=1$ and $R_{\mathrm{p}}=3 / 8$ (as in the case of Esu \& D'Elia (1974)) are used for the calculations. Fig. 5(a) displays the $t_{\mathrm{u}}-\lambda$ relation (where $t_{\mathrm{u}}=F_{\mathrm{n}} / F_{\mathrm{n}(\max )}$ ) provided by Viggiani (1981) at $\chi=0 \cdot 375$ and the computed results (solid lines) for various $y_{\mathrm{sn}}$, when $L_{\mathrm{n} 1}=1$. A full list of formulations of
Viggiani (1981) refers to Di Laora et al. (2017). The variation of $\lambda\left(=L_{\mathrm{n} 2} / L_{\mathrm{n} 1}\right)$ is achieved by fixing $L_{\mathrm{n} 1}$ while varying $L_{\mathrm{n} 2}$. As $y_{\text {sn }}$ increases, the solid lines tend to approach the solution of Viggiani (1981). Several lines can be drawn based on this calculation.

(a) $\lambda_{\text {ult }}$ is the ultimate value of $\lambda$, meaning that further increase of $L_{\mathrm{n} 2}$ only provides a negligible contribution to $t_{\mathrm{u}}$ (i.e. long pile in the stable layer) as all the solid curves become horizontal with large $\lambda$. In this study, $\lambda_{\text {ult }}$ is estimated by searching for the minimum $L_{\mathrm{n} 2}$, which provides the $t_{\mathrm{u}}$ value that has less than $0 \cdot 1 \%$ difference to the $t_{\mathrm{u}}$ value when $L_{\mathrm{n} 2}=10$. Note that $L_{\mathrm{n} 2}=10$ has been proved to provide a mode $\mathrm{C}$ behaviour for all the cases calculated in this paper.

(b) $\lambda_{\text {crit }}$ is the critical value of $\lambda$ where the maximum bending moment in the sliding layer $\left(M_{\mathrm{n} 1(\max )}\right)$ equals that in the stable layer $\left(M_{\mathrm{n} 2(\max )}\right)$ - that is, mode BY. This differs from the outcome of Di Laora et al. (2017), in which the failure mode BY is identified as a zone.

(c) $m_{\mathrm{u}}=M_{y \mathrm{n}} / L_{\mathrm{n} 1}^{2}$ : the contour lines (dashed lines) for the formation of plastic hinges in the pile provide a different level of pile section capacity $M_{y \mathrm{n}}$, and therefore various $m_{\mathrm{u}}$. It is also possible to determine the limit value $m_{\mathrm{u}(\lim )}=M_{y \mathrm{n}(\lim )} / L_{\mathrm{n} 1}^{2}$, meaning that additional pile section capacity would be the conservative part.

From Fig. 5(a), the evolution of the failure mechanism with soil displacement $y_{\mathrm{sn}}$ for different $\lambda$ ranges can be revealed. When $\lambda$ is smaller than about $0 \cdot 5$, modes $\mathrm{A}$ or $\mathrm{B} 1$ are prescribed. The boundary between modes A and B1 is not further explored considering the small pile resistance. A plastic hinge can only be formed in the sliding layer with a small level of $m_{\mathrm{u}}$ (smaller than about $0 \cdot 07$ ). When $\lambda$ lies between about 0.5 and 1 , with the increase of $y_{\mathrm{sn}}$, the pile response changes from the type of mode B1 to BY and finally becomes the type of B2. Failure mode depends on $m_{\mathrm{u}}$. When $\lambda$ is larger than 1 but smaller than about $1 \cdot 5$, pile response of the type of $\mathrm{B} 2$ is expected. A plastic hinge can be formed with $m_{\mathrm{u}}$ smaller than about $0 \cdot 65$. With even larger $\lambda$, failure mode $\mathrm{C}$ will finally take place, providing a pile section capacity of $m_{\mathrm{u}(\lim )}$ (about $\left.0 \cdot 7\right)$.

Similar observations are made for various $L_{\mathrm{n} 1}\left(L_{\mathrm{n} 1}=2\right.$ in Fig. 5(b) and $L_{\mathrm{n} 1}=3$ in Fig. 5(c)). However, $\lambda_{\text {ult }}$ becomes much smaller and $t_{\mathrm{u}}$ increases less with the soil displacement. Even though the final critical state seems to be approachable for unlimited soil displacement with pile section capacity larger than $m_{\mathrm{u}(\mathrm{lim})}$, the consideration of the pile response at an extremely large $y_{\mathrm{sn}}$ is meaningless, as the purpose of the pile installation is to prevent the landslide. For a row of infinitely rigid piles, it would imply that the piles are ineffective if the sliding soil has moved in the direction perpendicular to the pile row for a distance greater than half the pile diameter. Half the pile diameter is used here as the limit for $y_{\mathrm{sn}}$. Therefore, the maximum soil displacement in the non-dimensional model is given by

$$
y_{\mathrm{sn}(0.5 D)}=\frac{D}{2 y_{\mathrm{r}}}=\frac{k_{\mathrm{h} 1}}{2 p_{\mathrm{u} 1}}
$$

Equation (17) shows that $y_{\mathrm{sn}(0.5 D)}$ depends also on the soil properties of the sliding region. To make an example, a case of soft clay is considered $\left(k_{\mathrm{h}}=12.5 \mathrm{MPa} ; p_{\mathrm{u}}=112.5 \mathrm{kPa}\right)$, which gives $y_{\mathrm{sn}(0.5 D)}=55.6$.

The $t_{\mathrm{u}}-\lambda$ relationships at $y_{\mathrm{sn}(0.5 D)}$ for various $L_{\mathrm{n} 1}$ values are plotted in Fig. 5(d). $\lambda_{\text {crit }}$ seems to be slightly influenced by $L_{\mathrm{n} 1}$, while large variation of $\lambda_{\text {ult }}$ is observed. The $m_{\mathrm{u}}$ lines on the left side of $\lambda_{\text {crit }}$ are inclined, whereas on the right side they are horizontal, indicating that $m_{\mathrm{u}(\mathrm{lim})}$ depends only on $L_{\mathrm{n} 1}$ for 


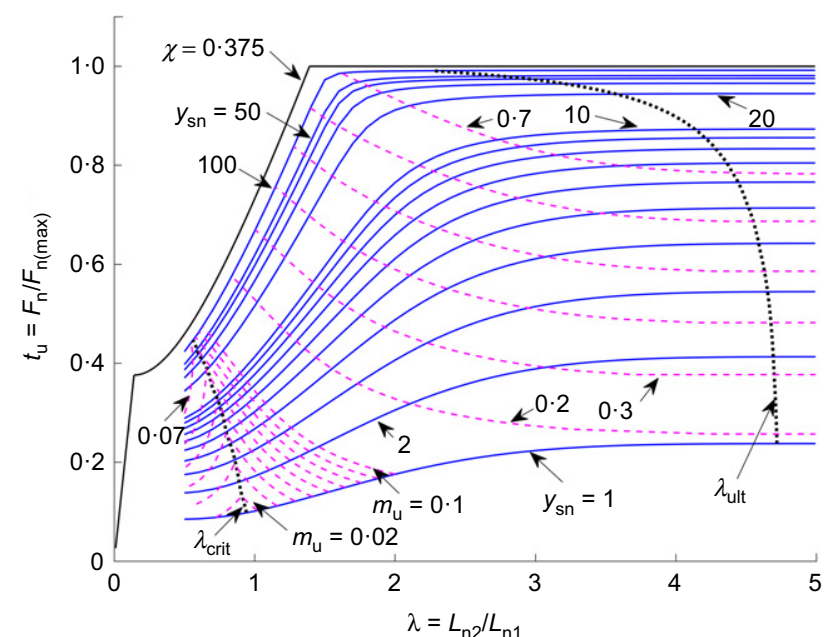

(a)

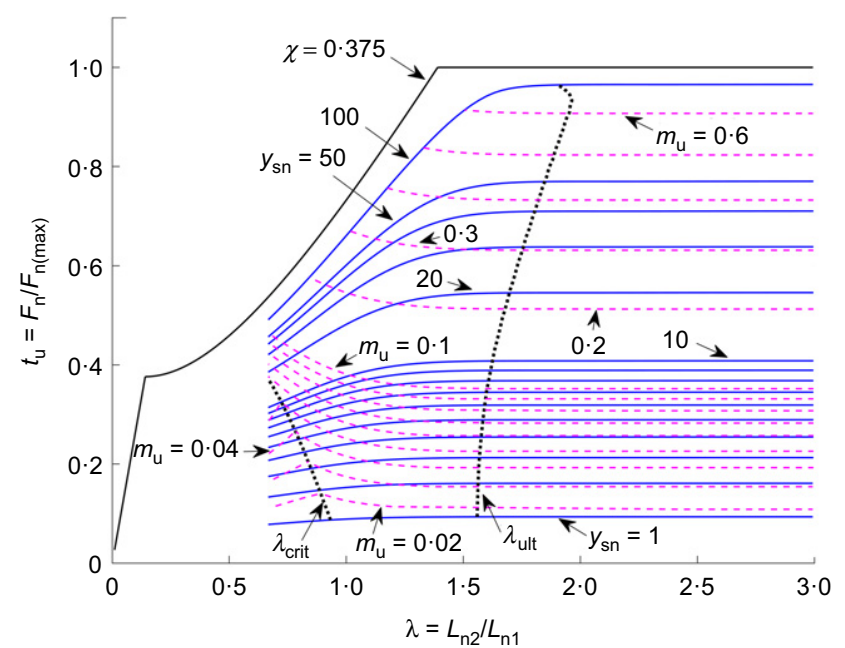

(c)

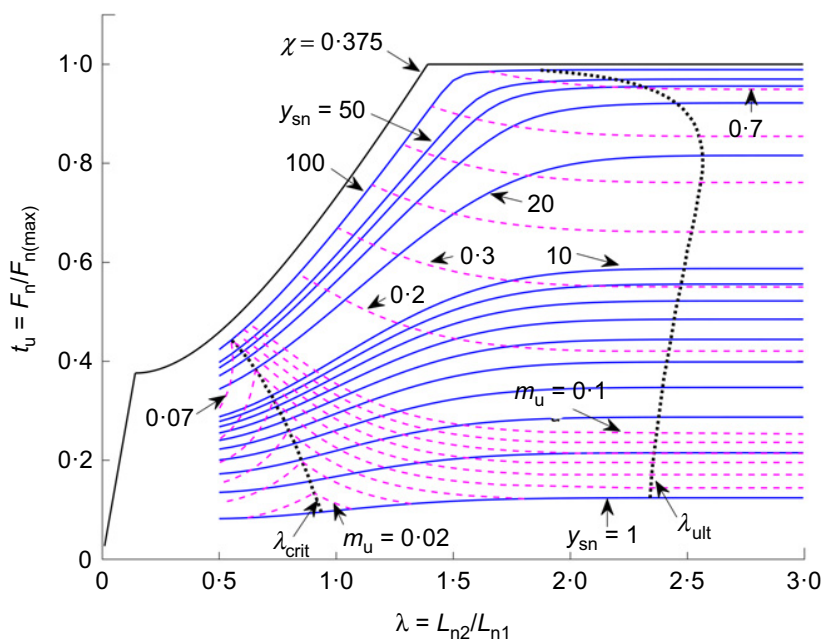

(b)

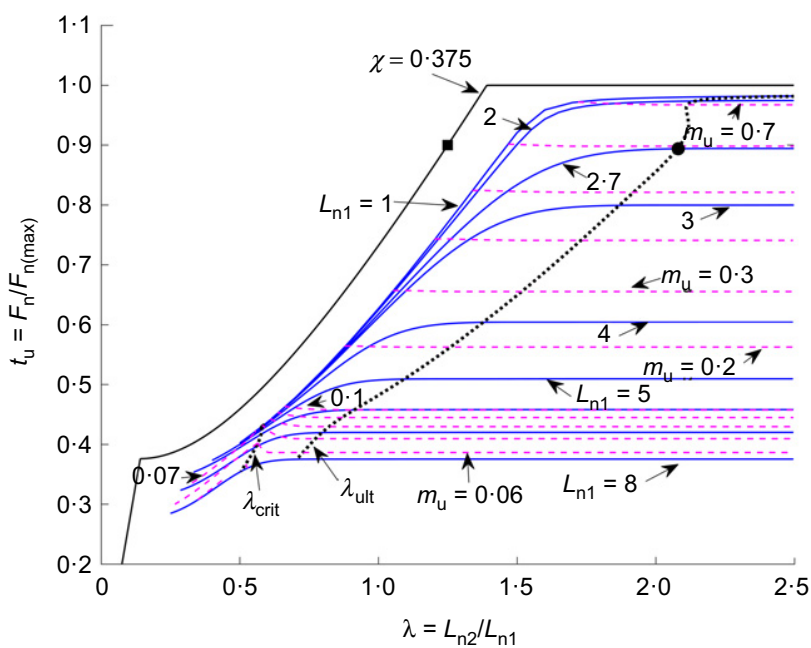

(d)

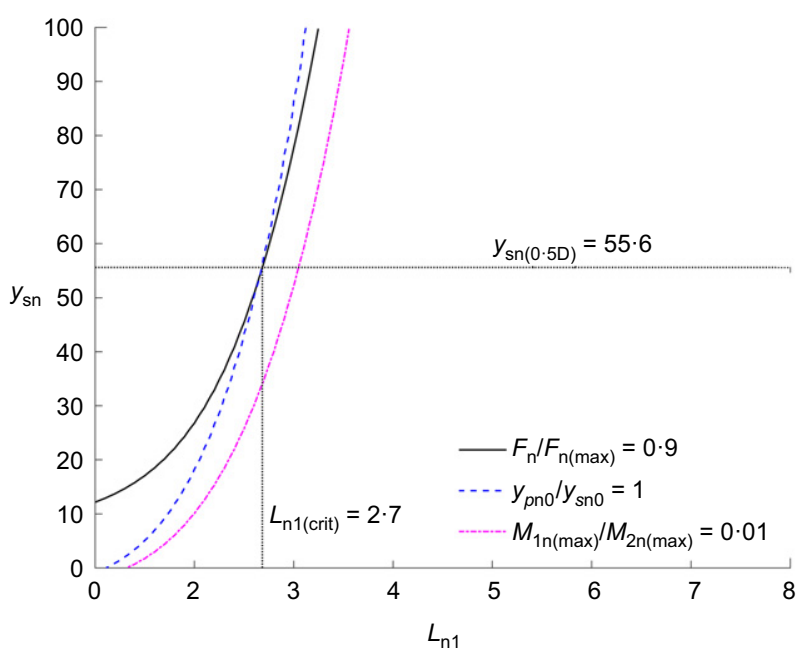

(e)

Fig. 5. The evolution of pile response with $L_{\mathrm{n} 1}$ and $y_{\mathrm{sn}}$. Variation of $t_{\mathrm{u}}-\lambda$ with $y_{\mathrm{sn}}$ when: (a) $L_{\mathrm{n} 1}=1$; (b) $L_{\mathrm{n} 1}=2$; (c) $L_{\mathrm{n} 1}=3$. (d) Variation of $t_{\mathrm{u}}-\lambda$ with $L_{\mathrm{n} 1}$ at $y_{\mathrm{sn}(0.5 D)}=55 \cdot 6$; (e) determination of $L_{\mathrm{n} 1(\mathrm{crit})}$

a certain soil displacement limit. Reduction of $t_{\mathrm{u}}$ is significant with increasing $L_{\mathrm{n} 1}$, which means that the mode $C$ type pile response may not occur for certain $L_{\mathrm{n} 1}$, even though the value of $\lambda$ suggests that. Since mode $C$ is the preferred pile response for slope stabilisation, it would be convenient to define a critical $L_{\mathrm{n} 1}$, which is the maximum $L_{\mathrm{n} 1}$ to provide the mode $\mathrm{C}$ type of pile response at $y_{\mathrm{sn}(0.5 D)}$. As observed previously, mode $\mathrm{C}$ differs from mode $\mathrm{B}$ in the features of relative pile-soil displacement at the pile head and the negative bending moment. Fig. 5(e) shows the contour lines of $t_{\mathrm{u}}=F_{\mathrm{n}} / F_{\mathrm{n}(\max )}=0.9, y_{\mathrm{pn} 0} / y_{\mathrm{sn} 0}=1$ and $M_{1 \mathrm{n}(\max )} / M_{2 \mathrm{n}}$ (max) $=0.01$ with varying $L_{\mathrm{n} 1}$ and $y_{\mathrm{sn}}$. On the right side of the curves, the pile top displacements are larger than the soil displacements, negative bending moments appear in the 
sliding layer and less than $90 \%$ of the maximum sliding force is mobilised. As $y_{\mathrm{sn}}$ increases, the $L_{\mathrm{n} 1}$ of the curves increase first rapidly, and then the increasing rate becomes much smaller when $y_{\mathrm{sn}}$ is larger than about 30 . In the following analysis, $F_{\mathrm{n}} / F_{\mathrm{n}(\max )}=0.9$ and $y_{\mathrm{sn}}=y_{\mathrm{sn}(0.5 D)}$ are used to

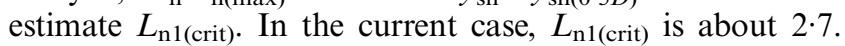
Provided $L_{\mathrm{n} 1 \text { (crit) }}$, the corresponding $\lambda_{\text {ult }}$ can be obtained in Fig. 5(d) (filled circle), which shows a large difference from the results in Viggiani (1981) (filled square). Note that $\lambda_{\text {ult }}$ may be slightly different, depending on the definition (here, less than $0 \cdot 1 \%$ difference in $t_{\mathrm{u}}$ compared to the case when $\left.L_{\mathrm{n} 2}=10\right)$.

\section{Effect of $\mathrm{R}_{\mathrm{k}}$ and $\mathrm{R}_{\mathrm{p}}$}

Previous analyses are based on a given set of $R_{k}$ and $R_{p}$, the values of which vary with the soil properties in both the sliding and stable layers. Generally, $k_{\mathrm{h}}$ and $p_{\mathrm{u}}$ of the stable soil are higher than that of the sliding layer - that is, both $R_{k}$ and $R_{p}$ should be smaller than 1 . To study the effect of stable soil, the sliding layer is fixed as a soft clay $\left(y_{\mathrm{sn}(0.5 D)}=55 \cdot 6\right)$. For each combination of $R_{k}$ and $R_{p}, L_{\mathrm{n} 1 \text { (crit) }}$ is obtained by assuming a long embedment - that is, $\lambda>\lambda_{\text {ult }}$, then $\lambda_{\text {ult }}$ is

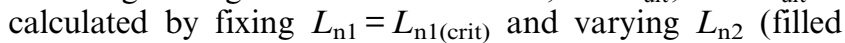
circle in Fig. 5(d)). The variations of $L_{\mathrm{n} 1 \text { (crit) }}$ and $\lambda_{\text {ult }}$ with $R_{k}$ and $R_{p}$ are, respectively, shown in Figs 6(a) and 6(b),

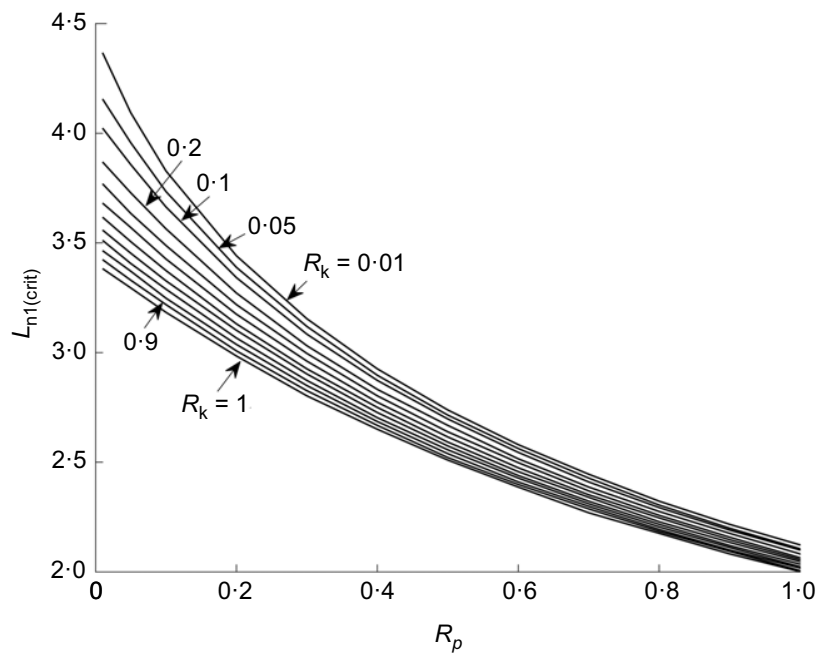

(a)

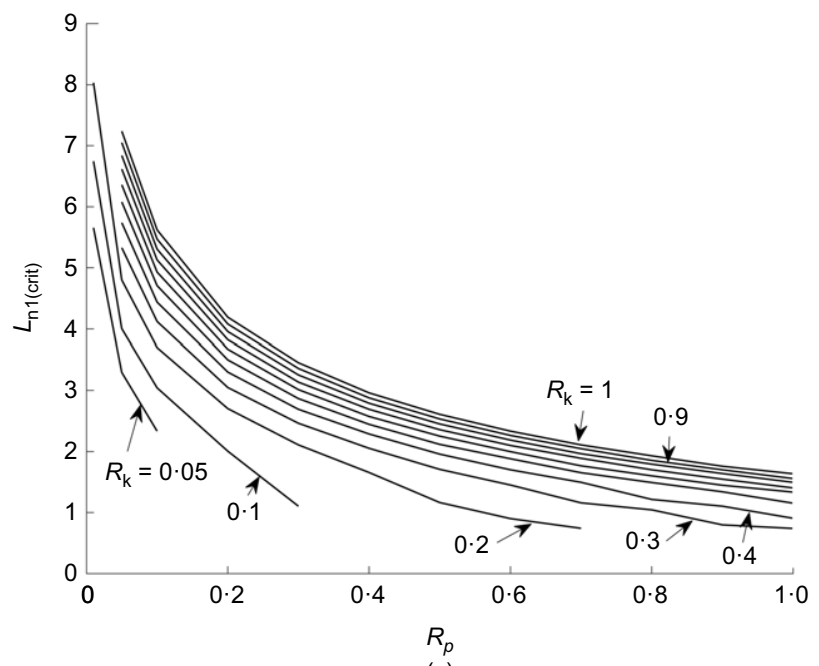

(c) indicating that $R_{p}$ has a much greater influence than $R_{k}$. The reason for this is that at a soil movement of $0 \cdot 5 D$, the maximum pile-soil contact pressure has been mobilised for the major part of the pile in the sliding layer. As a result, $R_{p}$ controls the pile response. Generally, $L_{\mathrm{n} 1 \text { (crit) }}$ increases and $\lambda_{\text {ult }}$ decreases with reducing $R_{k}$ and $R_{p}$ - that is, stiffer, stable soil tends to drag the pile response towards the type of mode $\mathrm{C}$ and shorter embedment length is needed. It is also observed that $\lambda_{\text {ult }}$ varies linearly with $R_{p}$ and the $\lambda_{\text {ult }}-R_{p}$ line approaches the solution of Viggiani (1981) (filled square in Fig. 5(d)) at an extremely low $R_{k}$. A greater effect of $R_{k}$ on the pile response is expected for the modes A and B.

When $R_{k}$ and $R_{p}$ vary due to the change of the sliding soil (i.e. $k_{\mathrm{h} 1}$ and $\left.p_{\mathrm{u} 1}\right)$, the non-dimensional parameters $y_{\mathrm{sn}(0.5 D)}$, $L_{\mathrm{n} 1}$ and $L_{\mathrm{n} 2}$ also vary. Calculations of each combination of $R_{k}$ and $R_{p}$ are performed by using a stiff clay $\left(k_{\mathrm{h} 2}=75 \mathrm{MPa}\right.$ and $\left.p_{\mathrm{u} 2}=1.2 \mathrm{MPa}\right)$ as the stable layer with $y_{\mathrm{sn}(0.5 D)}$ calculated by equation (17). The variations of $L_{\mathrm{n} 1 \text { (crit) }}$ and $\lambda_{\text {ult }}$ are, respectively, plotted in Figs 6(c) and 6(d), which also suggests the dominant role of $R_{p}$. The variation ranges of $L_{\mathrm{n} 1 \text { (crit) }}$ and $\lambda_{\text {ult }}$ in Figs 6(c) and 6(d) are larger than those in Figs 6(a) and $6(\mathrm{~b})$, meaning that the sliding layer has a greater impact than the stable layer. Therefore, the $p_{\mathrm{u}}$ profile in the sliding soil may need more attention in the pile design routine. A large difference between $\lambda_{\text {ult }}$ and the solution of Viggiani (1981) is observed and $\lambda_{\text {ult }}$ seems not to be affected by $R_{k}$,

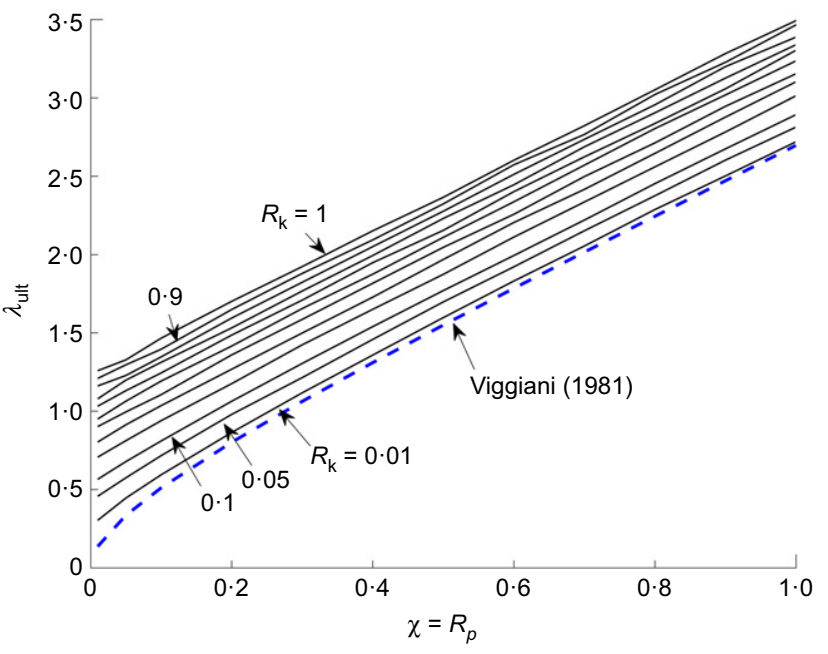

(b)

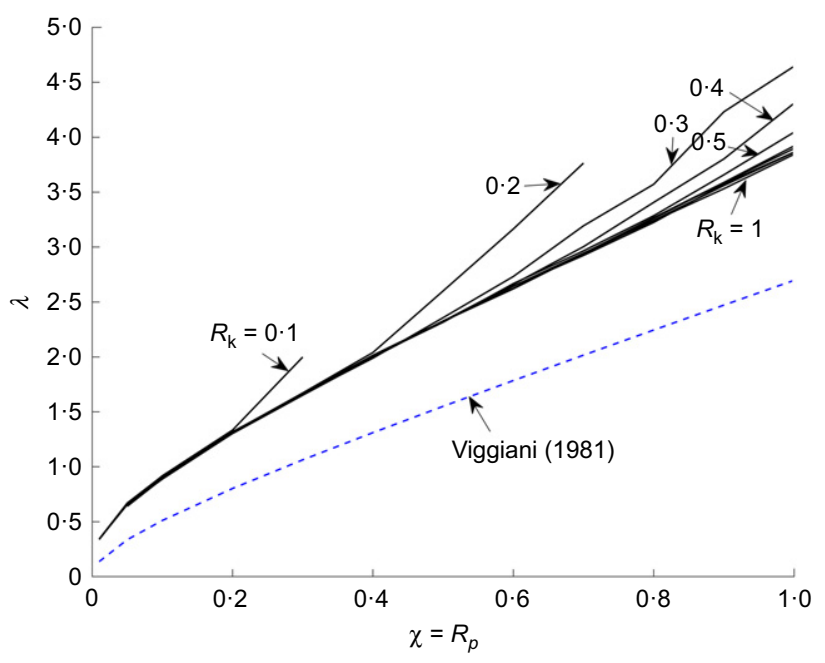

(d)

Fig. 6. The effect of $R_{k}$ and $R_{p}$. Variation of (a) $L_{\mathrm{n} 1 \text { (crit) }}$ and (b) $\lambda_{\mathrm{ult}}$ with $R_{k}$ and $R_{p}$ due to the change of stable soil. Variation of (c) $L_{\mathrm{n} 1(\mathrm{crit})}$ and (d) $\lambda_{\text {ult }}$ with $R_{k}$ and $R_{p}$ due to the change of sliding soil 
except for those cases where $R_{k}$ is much smaller than $R_{p}$, which, however, are unlikely to occur. In general, overestimated $R_{k}$ or $R_{p}$ results in underestimated $L_{\mathrm{n} 1 \text { (crit) }}$ and overestimated $\lambda_{\text {ult }}$, both resulting in conservative design; that is, a lower sliding force than expected.

Overall, the solution of Viggiani (1981), as expected from its assumptions of rigid pile and limit pile-soil contact pressure, can be seen as an upper bound for the $t_{\mathrm{u}}-\lambda$ space (Fig. 5(d)). As a result, it is likely to provide a nonconservative design - in other words, overestimated $t_{\mathrm{u}}$ and underestimated $\lambda$. The proposed non-dimensional solutions are able to take into account the effect of soil displacement and relative pile rigidity. Once the soil parameters are estimated $\left(R_{k}\right.$ and $\left.R_{p}\right)$, non-dimensional solutions are calculated and design charts are obtained covering the whole range of $y_{\mathrm{sn}}, L_{\mathrm{n} 1}$ and $L_{\mathrm{n} 2}$ (i.e. including the whole range of $D, E I, L_{1}$ and $L_{2}$ ), which has great potential in the design optimisation process.

\section{DISCUSSION ON THE ACCURACY}

The use of the proposed method may throw up some challenges regarding its accuracy, including the soil displacement profile, the $c_{\mathrm{u}}$ profile, the $k_{\mathrm{h}}-c_{\mathrm{u}}$ relationship, the $p_{\mathrm{u}}-c_{\mathrm{u}}$ relationship and so on.

Field measurements show that the movement of the sliding layer is uniform for some landslides, but more frequently it decreases approximately linearly from the slope surface to the sliding plane (Cai \& Ugai, 2011). As shown in Fig. 2, $\theta_{\mathrm{s}}=0$ represents the uniform case, while $\theta_{\mathrm{s}}>0$ is the case where the soil movement decreases linearly with depth. $\theta_{\text {sn }}$ is the corresponding parameter of $\theta_{\mathrm{s}}$ in the non-dimensional model (see Table 2), which can be readily incorporated in the calculations. Comparisons between the cases with and without $\theta_{\mathrm{sn}}$ show that its effect on the pile response is significant when $y_{\mathrm{sn}}$ is small or $L_{\mathrm{n} 1}>L_{\mathrm{n} 1 \text { (crit). Ignoring } \theta_{\mathrm{sn}}}$ gives rise to overestimated bending moments in the pile.

For the $k_{\mathrm{h}}-c_{\mathrm{u}}$ and the $p_{\mathrm{u}}-c_{\mathrm{u}}$ relationships, inaccurate selections will induce similar consequences for using different sliding or stable layers, which refer to the observations in the previous section entitled 'Effect of $R_{k}$ and $R_{p}$ ' and are not repeated here. When assuming constant $k_{\mathrm{h}}-c_{\mathrm{u}}$ and $p_{\mathrm{u}}-c_{\mathrm{u}}$ relationships, the variation of the distribution of $c_{\mathrm{u}}$ affects both profiles of $k_{\mathrm{h}}$ and $p_{\mathrm{u}}$. As the model normalisation is based on $k_{\mathrm{h}}$, the non-uniform distribution of $k_{\mathrm{h}}$ can only be considered by using a representative $k_{\mathrm{h}}$ for the whole soil layer. Its influence refers to the effect of $R_{k}$. As for the $p_{\mathrm{u}}$ distribution, it may be reasonable to give smaller values from the ground surface to a certain depth (Broms, 1964; Ito \& Matsui, 1975; Viggiani, 1981; Kanagasabai et al., 2011), which has a great influence on $F_{\mathrm{n}}$ and $M_{\mathrm{n} 2(\max )}$ when $L_{\mathrm{n} 1}<L_{\mathrm{n} 1 \text { (crit) }}$.

The proposed model is based on the simplified ground model of uniform $c_{\mathrm{u}}$ profile and assuming constant $k_{\mathrm{h}}-c_{\mathrm{u}}$ and $p_{\mathrm{u}}-c_{\mathrm{u}}$ relationships. This ground model is often considered reasonable in overconsolidated clay soil. As concluded previously, $R_{p}$ and the profile of $p_{\mathrm{u} 1}$ and $y_{\mathrm{sn}}$ may have a great impact on the model accuracy. This can be improved by modifying the ground model, such as using the measured soil displacement profile and calibrating the $p_{\mathrm{u}}$ and $k_{\mathrm{h}}$ profiles through field testing or advanced numerical studies. It will be demonstrated in the next section that, given calibrated parameters, the proposed model can deliver satisfactory results.

\section{NUMERICAL VERIFICATION}

In this section, the accuracy of the proposed method is verified against $3 \mathrm{D}$ finite-element simulations carried out using the numerical code Abaqus. First, the modelling details are provided. Second, the soil parameters are calibrated and the $p_{\mathrm{u} 1}$ profile is obtained. Finally, the simulated results of four test series are used to demonstrate the predictive efficacy of the proposed method.

\section{Numerical model}

The geometry of the numerical model is displayed in Fig. 7; it consists of a $L_{1}+L_{2}$ long pile with a diameter of $1 \mathrm{~m}$. The distance from the pile tip to the model bottom is four diameters. The pile axis is five diameters away from all the side boundaries, representing a pile-to-pile spacing of ten diameters perpendicular to the sliding direction (Kourkoulis et al., 2011). The finite-element meshes exploit symmetry, so that only one half of the model needs to be discretised. The pile is assumed to behave as an elastic material while plasticity in the cohesive soils is considered. The constitutive model for cohesive soils proposed by Gerolymos \& Gazetas (2006) is adopted, consisting of a non-linear kinematic hardening law in conjunction with a von Mises envelope as the bounding surface and an associated plastic flow law. Generally, this constitutive model predicts well the behaviour of clay deposits in the analysis of soil-structure interactions under both monotonic and cyclic loads (Zafeirakos \& Gerolymos, 2013; Gerolymos et al., 2020, 2015). The material properties for both the pile and soils are listed in Table 4. Three additional parameters are defined (Gerolymos $\&$ Gazetas, 2006): $\sigma_{0}$ is the stress at zero plastic strain, which is usually expressed as a small fraction of the uniaxial strength (1/20-1/5), and $C$ and $\gamma$ are hardening parameters that define the maximum transition of the yield surface. $C$ is obtained as equal to the modulus of elasticity $(E)$ by differentiating the back-stress with respect to the plastic strain. $\gamma$ is obtained by

$$
\gamma=\frac{E}{\sqrt{3} c_{\mathrm{u}}-\sigma_{0}}
$$

Interface elements are used to model both the interaction between the pile and the surrounding soils and the slippage between the two soil layers. The friction coefficient 0.3 is used for the former, whereas a frictionless interface is used for the latter. Sliding and detachment of the interfaces are allowed that is, geometric non-linearities are considered. For all of the side boundaries, the bottom boundary and the symmetry boundary, the movement perpendicular to the boundary is restrained. The soil movement is simulated by applying

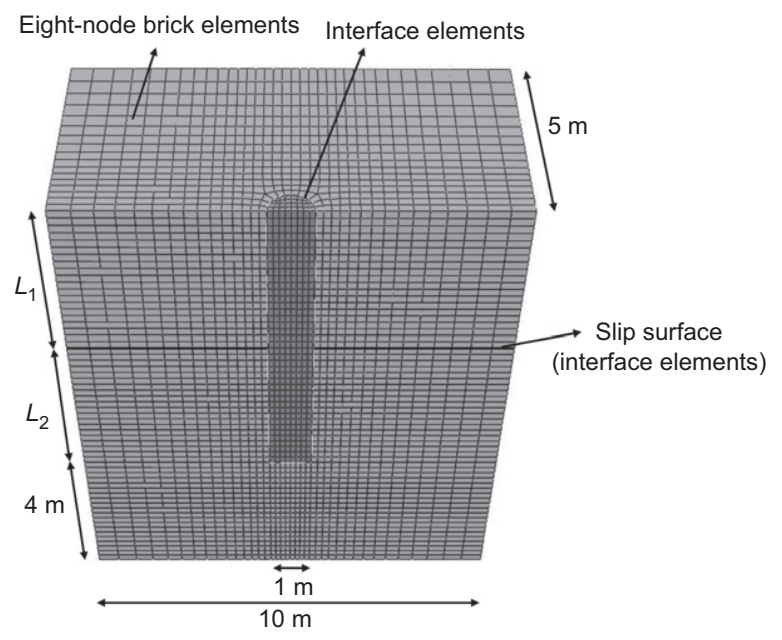

Fig. 7. Mode geometry and 3D finite-element mesh 
Table 4. Numerical simulation parameters

\begin{tabular}{l|r|c|c|c|c|c|c}
\hline Material & $E: \mathrm{MPa}$ & $\mu$ & $\rho: \mathrm{kg} / \mathrm{m}^{3}$ & $c_{\mathrm{u}}: \mathrm{kPa}$ & $\sigma_{0}: \mathrm{kPa}$ & $C=E: \mathrm{MPa}$ & $\gamma$ \\
\hline Pile & 25000 & $0 \cdot 2$ & 2500 & $\overline{30}$ & $\overline{5 \cdot 20}$ & $\overline{12}$ & $-\overline{2}$ \\
Soft clay & 12 & $0 \cdot 45$ & 2000 & 80 & $13 \cdot 86$ & 32 & $256 \cdot 6$ \\
Medium clay & 32 & $0 \cdot 45$ & 2000 & 80 & \\
\hline
\end{tabular}

horizontal displacement (up to $0 \cdot 5 \mathrm{D}$ ) at both the front and rear boundaries of the top layer.

\section{Parameter calibration}

To reproduce the pile response from the finite-element model using the proposed method, basic parameters namely, $k_{\mathrm{h}}$ and $p_{\mathrm{u}}$ for both soil layers - must be calibrated. For this purpose, a failure mode in which the ultimate lateral capacity is mobilised in both soil layers (i.e. mode B) should be obtained. The case $L_{1}=L_{2}=4 \mathrm{~m}(\lambda=1)$ has been selected. As widely reported in both numerical simulations and field observations (Broms, 1964; Ito \& Matsui, 1975; Viggiani, 1981; Kanagasabai et al., 2011), $p_{\mathrm{u} 1}$ near the ground surface (shallower than about $1.5 D$ ) may be significantly lower than the deeper soil. Viggiani (1981) adopted a simple solution by reducing $L_{1}$ for the analysis. The proposed method can also be modified to consider this effect by applying linearly increasing $p_{\mathrm{u} 1}$ near the ground surface while still using $p_{\mathrm{u} 1}$ of deep soil for the normalisation. To obtain the $p_{\mathrm{u} 1}$ profile, another numerical simulation $\left(L_{1}=4 \mathrm{~m}\right.$, $L_{2}=8 \mathrm{~m}$ ), which delivers the mode $\mathrm{C}$ pile response is needed (i.e. $p_{\mathrm{u}}$ is attained only in the sliding layer).

Depth profiles of the pile displacement, bending moment and shear force are readily extracted from the numerical model. The depth profile of pile-soil contact pressure $(p)$ and thus the $p-y$ curves are derived by differentiating the shear force with respect to depth. Fig. 8(a) shows the $p$ profile increasing with soil displacement $\left(y_{\mathrm{s}}\right)$ for the case $\lambda=1$. It is obvious that near the pile rotation points $(z=\sim 0.5 \mathrm{~m}$ and $\sim 6.5 \mathrm{~m}$ ), the developed relative lateral pile-soil displacement appears to be too small to mobilise the ultimate lateral capacity (Byrne et al., 2020). Apart from that, the abnormal result is also observed near the slip surface, which is influenced by local vertical stress reduction due to pile-soil gapping (Kanagasabai et al., 2011). Therefore, the $p-y$ curves

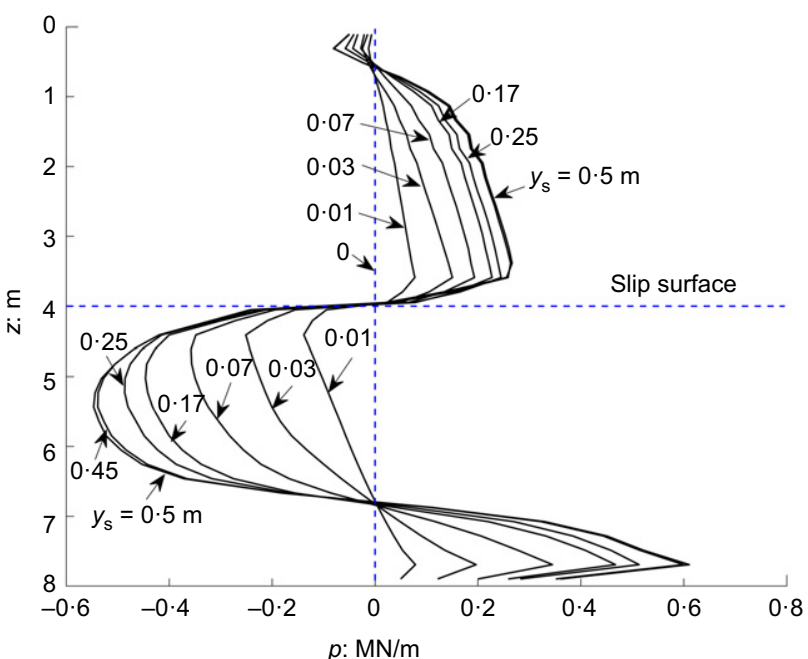

(a)

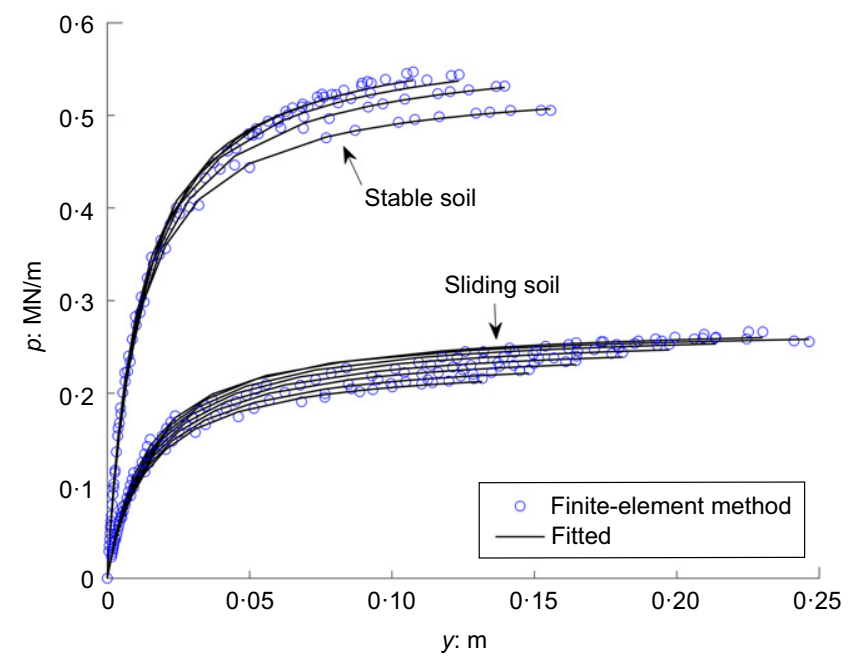

(b)

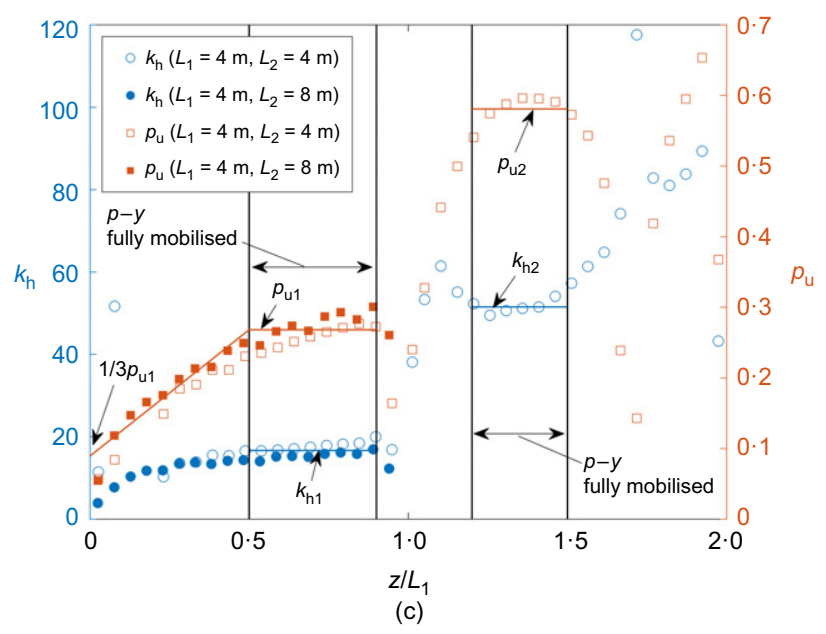

Fig. 8. Parameter calibration: (a) variation of $p$ profile with $y_{\mathrm{s}}$; (b) fitted $p-y$ curves; (c) selections of parameters representing the soil layers and the $p_{\mathrm{u} 1}$ profile 
used for calibration need to be carefully selected. A two-step calibration is conducted. First, curve fitting is applied for each extracted $p-y$ curve. The initial $p_{\mathrm{u}}$ is set to the maximum $p$ in that $p-y$ curve. Initial $k_{\mathrm{h}}$ can be calculated by equation (4), using $y_{\mathrm{r}}$ (i.e. $y_{50}$ ) as the $y$ value where half of the maximum $p$ occurs. The final parameters are selected by varying both $p_{\mathrm{u}}$ and $k_{\mathrm{h}}$ and minimising the least-square error between the numerical data and the fitted hyperbolic $p-y$ curve. Second, parameters at valid depths are selected to generate the parameters for the layer. As shown in Fig. 8(c), excluding the previously mentioned areas, two depth ranges with fully mobilised soil reactions are identified. The results of the case $\lambda=2$ ( $p_{\mathrm{u}}$ attained only above the slip surface) are also plotted, showing good agreement for the identified range above the slip surface. Reduction of $p_{\mathrm{u}}$ is observed due to the influence of soil heaving near the ground surface. Final $p_{\mathrm{u}}$ and $k_{\mathrm{h}}$ for each layer are obtained by averaging the data in each identified depth range. For the $p_{\mathrm{u}}$ variation near the ground surface, a linear increase with $1 / 3 p_{\mathrm{u} 1}$ at $z=0$ appears to fit the data well from the case $\lambda=2$ (filled squares). Note that there is no pile rotation point above the slip surface for the case $\lambda=2$; therefore, the ultimate lateral capacity near the surface is obtained using only this calculation. A comparison of the numerical $p-y$ curves and the fitted data in the fully mobilised depth ranges is given in Fig. 8(b).

The calibration results are given in Table 5. The above two numerical calculations are well reproduced. The profiles of pile displacement, bending moment, shear force and soil pressure are compared in Fig. 9(a), while the histories of the pile resistance and the bending moment at the slip surface are checked in Figs 9(b) and 9(c), respectively.

Table 5. Calibration results

\begin{tabular}{l|c|c|c|c|c|c|c|c}
\hline No. & $L_{1}: \mathrm{m}$ & $L_{2}: \mathrm{m}$ & $k_{\mathrm{h} 1}: \mathrm{MPa}$ & $k_{\mathrm{h} 2}: \mathrm{MPa}$ & $p_{\mathrm{u} 1}: \mathrm{kPa}$ & $p_{\mathrm{u} 2}: \mathrm{kPa}$ & $R_{k}$ & $R_{p}$ \\
\hline 1 & 4 & 4 & $16 \cdot 69$ & $51 \cdot 54$ & $268 \cdot 2$ & $580 \cdot 9$ & $0 \cdot 32$ & $0 \cdot 46$ \\
2 & 4 & 8 & $16 \cdot 69$ & - & $268 \cdot 2$ & - & $0 \cdot 32$ & $0 \cdot 46$ \\
\hline
\end{tabular}
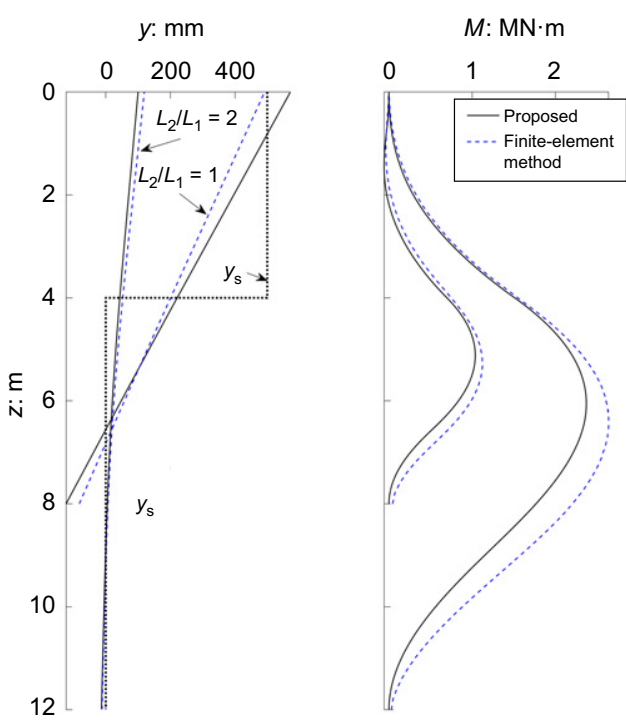

(a)

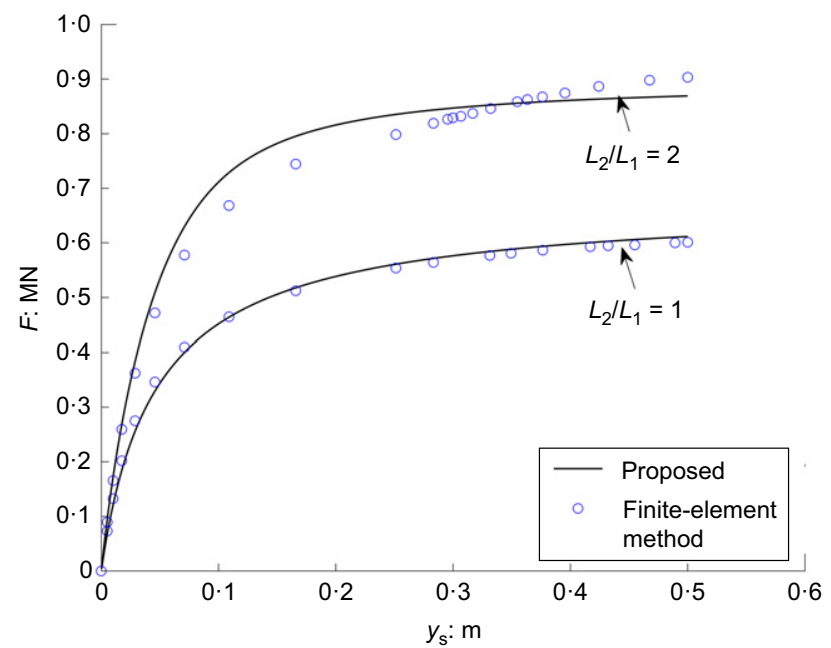

(b)
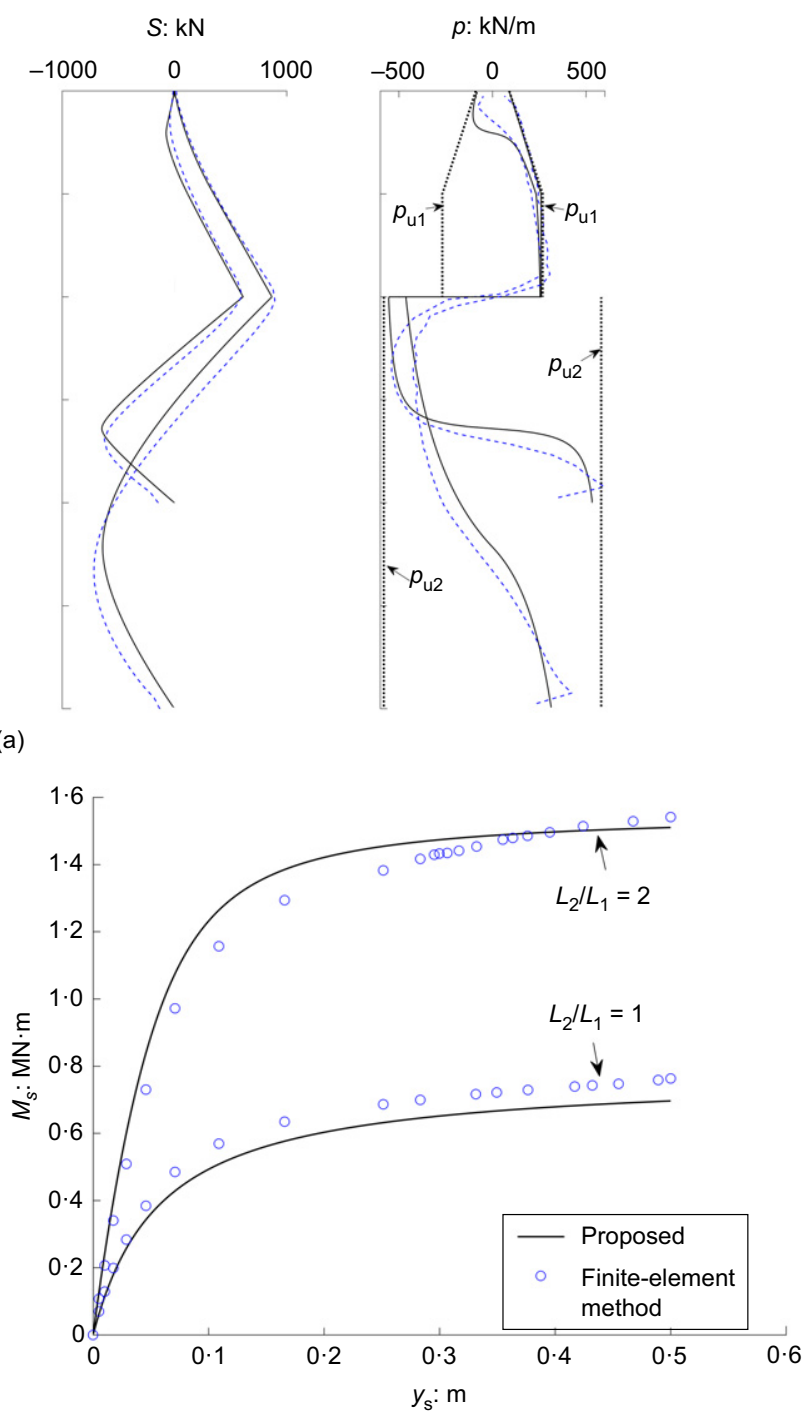

(c)

Fig. 9. Reproducing the calibrated simulations: (a) comparison of the depth profiles of pile displacement, bending moment, shear force and soil

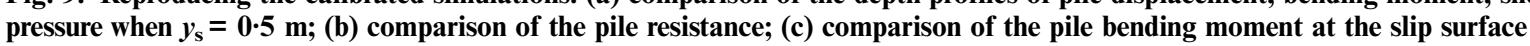


Predictive efficacy

Once the soil parameters have been calibrated, the pile response can be predicted for arbitrary combination of $L_{\mathrm{n} 1}$ and $\lambda$. To demonstrate the predictive efficacy of the proposed model, four series of simulation cases are performed and the configurations are specified in Table 6. The $F_{\mathrm{n}} / F_{\mathrm{n}(\max )}-\lambda$, $M_{\mathrm{ns}} / L_{\mathrm{n} 1}{ }^{2}-\lambda, M_{\mathrm{n} 1 \text { (max) }} / L_{\mathrm{n} 1}{ }^{2}-\lambda$ and $M_{\mathrm{n} 2 \text { (max) }} / L_{\mathrm{n} 1}{ }^{2}-\lambda$ relationships are shown in Fig. 10. In general, the transition from mode B to mode $\mathrm{C}$ is well predicted for all the tested $L_{\mathrm{n} 1}$ values. As for the accuracy, the mean difference between the proposed method and the finite-element method for $F$ and $M_{\mathrm{S}}$ is around $5 \%$, and $9 \cdot 2 \%$ for $M_{2(\max )}$. The maximum difference of around $15 \%$ is observed in both $M_{\mathrm{s}}$ and $M_{2(\max )}$. The difference in $M_{1(\max )}$ is not calculated due to its relatively small magnitude. However, it shows better agreement, which also supports the finding that the mode transition is well estimated. In the view of the current authors, the accuracy can be seen as satisfactory provided that so few parameters are used in the proposed method.

\section{APPLICATION OF THE NON-DIMENSIONAL SOLUTION}

This paper has provided some charts that are useful for pile design. However, as emphasised earlier, these results are based on specific $R_{k}, R_{p}$ and $y_{\mathrm{sn}(0.5 \mathrm{~B})}$ values. The calculation process can be readily implemented in any coding program. For an existing landslide, $k_{\mathrm{h}}$ and $p_{\mathrm{u}}$ are obtained using in situ or laboratory test results (i.e. given $R_{k}$ and $R_{p}$ ). Then, design charts like Fig. 5 can be easily generated and used for the

Table 6. Numerical simulation configurations

\begin{tabular}{l|c|c|c|r|r}
\hline Case series & $L_{1}: \mathrm{m}$ & $L_{2}: \mathrm{m}$ & $E I: \mathrm{MN} \mathrm{M}$ & $L_{\mathrm{n} 1}$ & $\lambda=L_{2} / L_{2}$ \\
\hline 1 & 4 & $4,6,8,10$ & $1227 \cdot 2$ & $1 \cdot 37$ \\
2 & 6 & $4,6,8,10$ & $1227 \cdot 2$ & $2 \cdot 05$ \\
3 & 6 & $4,6,8,10$ & $613 \cdot 6$ & $2 \cdot 44$ \\
4 & 6 & $4,6,8,10$ & $245 \cdot 4$ & $3 \cdot 06$ \\
\hline
\end{tabular}

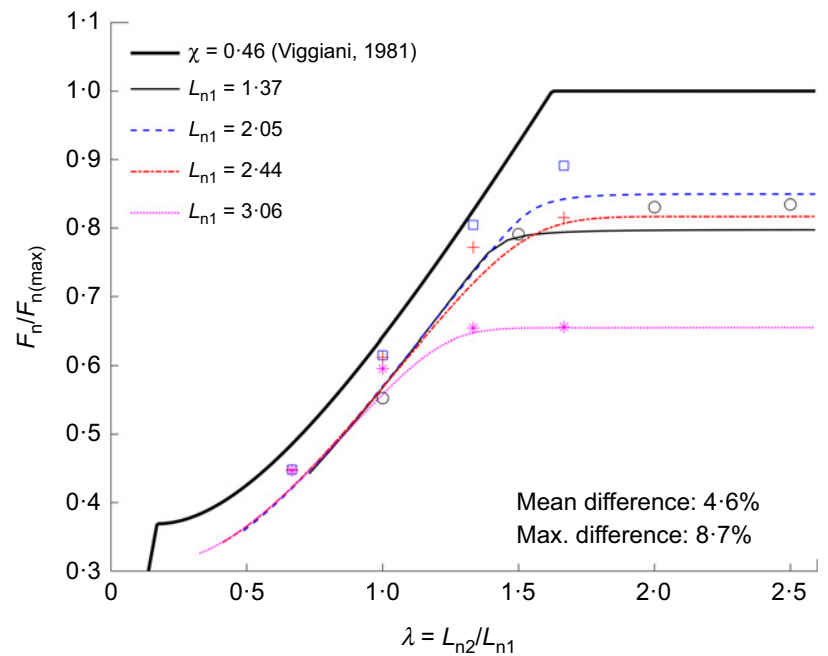

(a)

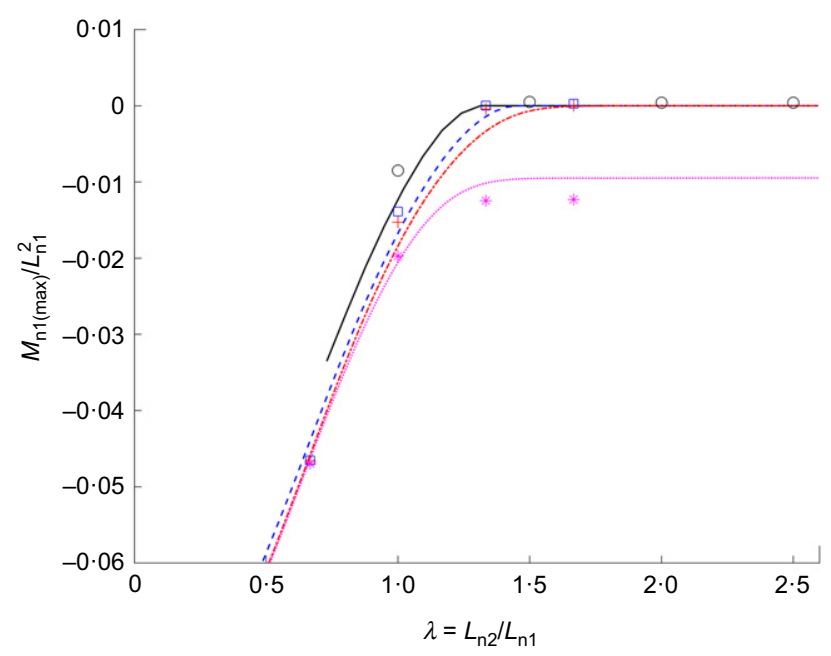

(c)

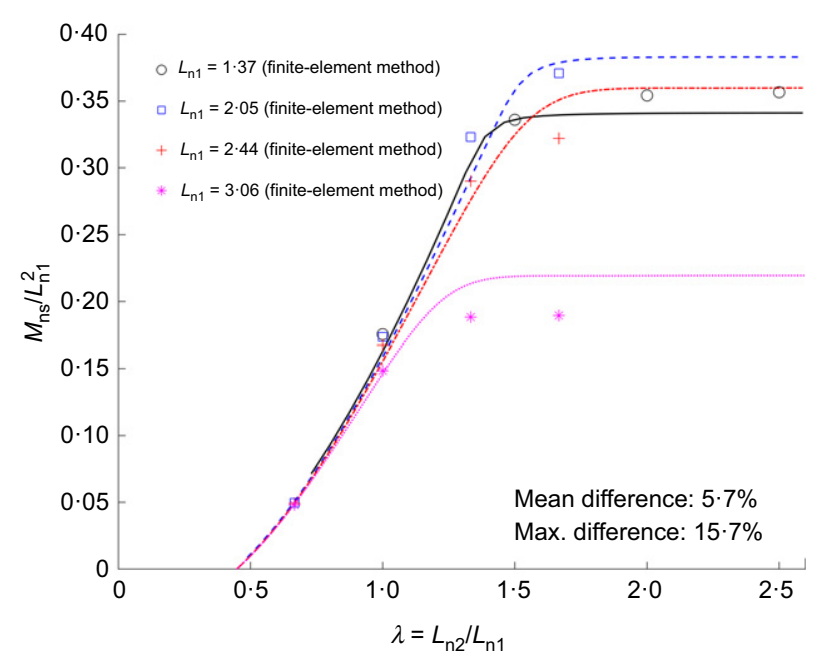

(b)

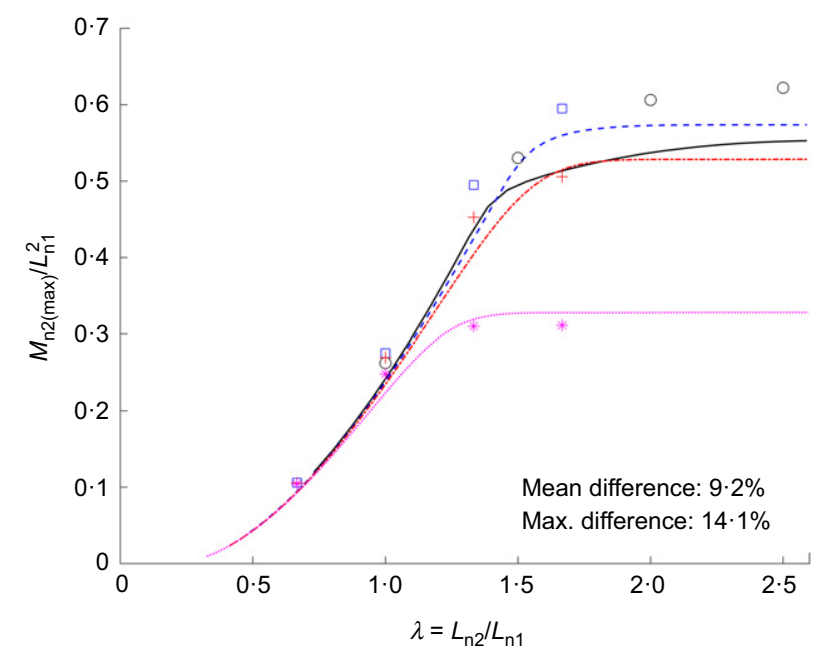

(d)

Fig. 10. Reproducing the finite-element method simulations. Variations of (a) $F_{\mathrm{n}} / F_{\mathrm{n}(\max )}$, (b) $M_{\mathrm{ns}} / L_{\mathrm{n} 1}{ }^{2}$, (c) $M_{\mathrm{n} 1(\max )} / L_{\mathrm{n} 1}{ }^{2}$ and (d) $M_{\mathrm{n} 2(\max )} / L_{\mathrm{n} 1}{ }^{2}$ with $\lambda$ 


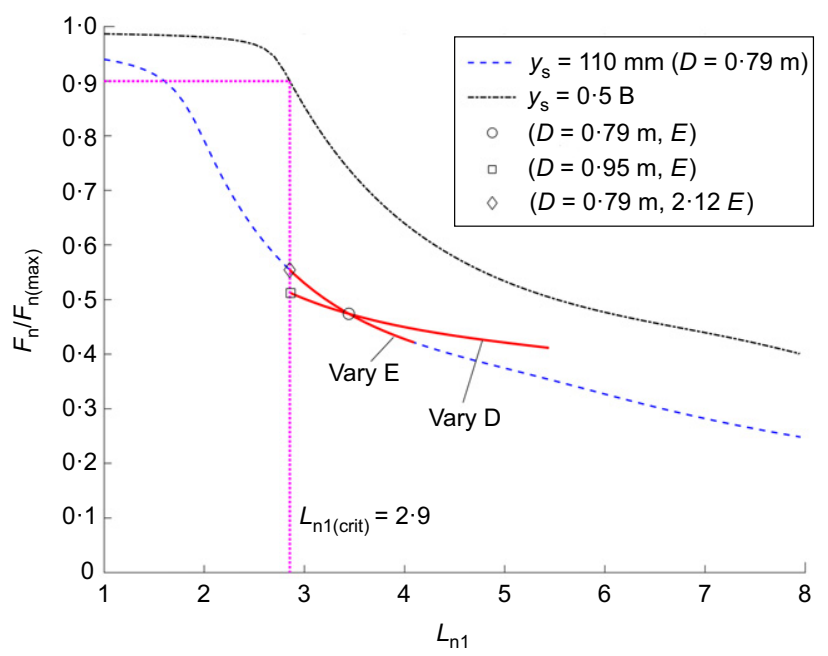

(a)
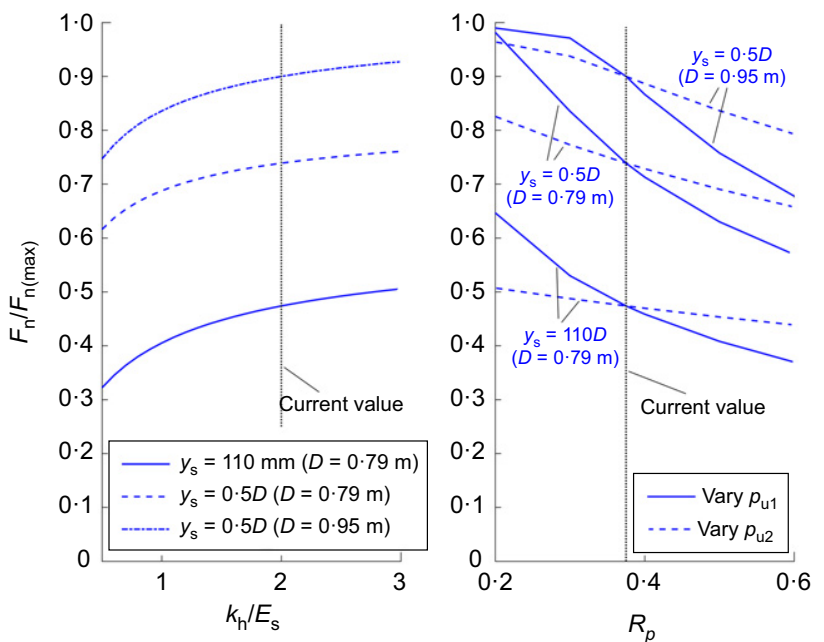

(b)

Fig. 11. Application of the non-dimensional solution in the case of Esu \& D'Elia (1974): (a) pile response prediction for various pile configurations; (b) sensitivity analysis of soil parameters

response prediction of any pile type (different $E I$ and $D$, represented by various $L_{\mathrm{n} 1}$ and $y_{\mathrm{sn}}$ ). For instance, the computed data for the presentation of Fig. 5 can be applied to the case of Esu \& D'Elia (1974). In Fig. 11(a), curves are extracted according to the parameters of the case history. The figure shows that the reinforced concrete pile used to stabilise the slope (hollow circle) lies in the mode B range and cannot provide maximum resistance. Moreover, for the explored conditions, varying $D$ greater than $0.95 \mathrm{~m}$ or increasing the pile elastic modulus more than $2 \cdot 12$ times that of the current pile, the pile response moves to the mode $\mathrm{C}$ range. The calculation data used for the design charts of Fig. 6 can be used to perform sensitivity analyses of soil parameters, as shown in Fig. 11(b). The prediction of $F_{\mathrm{n}} / F_{\mathrm{n}}$ (max) may be unconservative if higher $k_{\mathrm{h}} / E_{\mathrm{s}}$ or lower $R_{p}$ are estimated. More attention needs to be paid to $p_{\mathrm{u} 1}$, which influences the results the most. Such analysis is done directly using the calculation data created for the previous figures. Furthermore, a database can be created in advance for commonly encountered ranges of soil parameters, which can increase the efficiency of the preliminary pile design workflow.

\section{CONCLUSIONS}

The response of stabilising piles for landslide prevention is studied by way of a non-dimensional model based on a simplified ground model consisting of two layers of cohesive soils. The soil reaction is described by a hyperbolic $p-y$ model, which has been verified through three case studies. The failure modes identified by Viggiani(1981) have been further studied considering the effect of the soil displacement and the relative pile rigidity. $L_{\mathrm{n} 1 \text { (crit) }}$ and $\lambda_{\mathrm{ult}}$, which determine the mode $\mathrm{C}$ pile response, have been identified. The effects of stable and sliding soils have been explored and other influencing factors have been discussed. The efficacy of the proposed approach was demonstrated by the satisfactory result that it achieves in reproducing the more complex 3D finite-element analyses. The non-dimensional model has only four basic parameters related to pile and soil properties, and two parameters related to the soil movement profile. The model provides the opportunity to generate a database in advance, increasing the efficiency of the preliminary pile design workflow.

\section{ACKNOWLEDGEMENTS}

Authors G. L. and D. S. acknowledge the financial support provided by the National Natural Science Foundation of China under grant nos. 51878416 and 51938008 . The authors would like to thank $\mathrm{Mr} \mathrm{Wu}$ Zexiong for his assistance with the numerical simulations.

\section{NOTATION}

$C$ hardening parameter of the cohesive soil $\left(\mathrm{FL}^{-2}\right)$

$c_{\mathrm{u}}$ undrained shear strength of the soil $\left(\mathrm{FL}^{-2}\right)$

$D$ pile diameter (L)

$E$ Young's modulus of the pile $\left(\mathrm{FL}^{-2}\right)$

$E_{\mathrm{s}}$ soil elastic modulus $\left(\mathrm{FL}^{-2}\right)$

$F$ sliding force applied on the pile $(\mathrm{F})$

$I$ second moment of inertia for the pile's cross-section $\left(\mathrm{L}^{4}\right)$

$k_{\mathrm{h}}$ coefficient of subgrade reaction $\left(\mathrm{FL}^{-2}\right)$

$k_{\mathrm{sec}}$ secant modulus of the soil reaction $\left(\mathrm{FL}^{-2}\right)$

$L_{1} \quad$ pile length in the sliding layer (L)

$L_{2}$ pile length in the stable layer (L)

$L_{\mathrm{c} 1}$ critical length of an active long pile in the sliding layer $(\mathrm{L})$

$M$ pile bending moment (FL)

$M_{\mathrm{s}}$ pile bending moment at the slip surface (FL)

$M_{\mathrm{y}}$ pile section capacity (FL)

$m_{\mathrm{u}}$ normalised pile section capacity

$N_{\mathrm{p}} \quad$ limit yield pressure coefficient

$p$ soil-pile contacting force per unit pile length $\left(\mathrm{FL}^{-1}\right)$

$p_{\mathrm{u}} \quad$ ultimate pile-soil contact pressure $\left(\mathrm{FL}^{-2}\right)$

$R_{k}$ ratio of the modulus of the subgrade reaction

$R_{p} \quad$ ratio of the ultimate soil pressure on pile

$S$ pile shear force (F)

$T$ relative stiffness factor $(\mathrm{L})$

$t_{\mathrm{u}}$ pile resistance normalised by its theoretical maximum value

$x_{\mathrm{p} 1}$ thickness of the plastic zone in the sliding layer $(\mathrm{L})$

$y$ absolute displacement difference between the pile and soil at the same depth (L)

$y_{50}$ pile displacement corresponding to $50 \% p_{\mathrm{u}}(\mathrm{L})$

$y_{\mathrm{p}}$ pile displacement $(\mathrm{L})$

$y_{\mathrm{r}}$ reference displacement (L)

$y_{\mathrm{s}} \quad$ soil movement $(\mathrm{L})$

$y_{\mathrm{sn}(0.5 D)} \quad y_{\mathrm{sn}}$ corresponds to $0.5 \mathrm{D}$ soil displacement

$z$ depth measured from the ground surface (L)

$\beta$ relative stiffness factor for pile length normalisation $\left(\mathrm{L}^{-1}\right)$

$\gamma$ hardening parameter of the cohesive soil

$\Delta()$ increment of the parameter

$\theta$ rotation of the pile cross-section

$\theta_{\mathrm{s}}$ angle between the soil displacement profile and the vertical line 
$\lambda$ ratio of the embedded length to the pile length in the sliding layer

$\mu$ Poisson's ratio

$\rho$ soil density $\left(\mathrm{FL}^{-3}\right)$

$\sigma_{0} \quad$ soil stress at zero plastic strain $\left(\mathrm{FL}^{-2}\right)$

$\chi$ ratio of the soil lateral capacity between the sliding and stable layers

Oo parameter value at the pile top or ground surface

$O_{1}$ parameter for the sliding layer

$\mathrm{O}_{2}$ parameter for the stable layer

$O_{\text {crit }}$ critical value of the parameter

Olim limit value of the parameter

$O_{\max }$ maximum value of the parameter

$\mathrm{O}_{n} \quad$ normalised version of the parameter

Oult ultimate value of the parameter

\section{REFERENCES}

API (American Petroleum Institute) (2000). Recommended practice for planning, designing and constructing fixed offshore platforms working stress design. Washington, DC, USA: API.

Broms, B. B. (1964). Lateral resistance of piles in cohesive soils. J. Geotech. Engng Div. 90, No. 2, 27-63.

Byrne, P. M., Anderson, D. L. \& Janzen, W. (1984). Response of piles and casings to horizontal free-field soil displacements. Can. Geotech. J. 21, No. 4, 720-725, https://doi.org/10.1139/ t84-079.

Byrne, B. W., Houlsby, G. T., Burd, H. J., Gavin, K. G., Igoe, D. J. P., Jardine, R. J., Martin, C. M., McAdam, R. A., Potts, D. M., Taborda, D. M. G. \& Zdravković, L. (2020). PISA Design model for monopiles for offshore wind turbines: application to a stiff glacial clay till. Géotechnique 70, No. 11, 1030-1047, https:// doi.org/10.1680/jgeot.18.P.255.

Cai, F. \& Ugai, K. (2003). Response of flexible piles under laterally linear movement of the sliding layer in landslides. Can. Geotech. J. 40, No. 1, 46-53, https://doi.org/10.1139/T02-103.

Cai, F. \& Ugai, K. (2011). A subgrade reaction solution for piles to stabilise landslides. Géotechnique 61, No. 2, 143-151, https://doi.org/10.1680/geot.9.P.026.

Carrubba, P., Maugeri, M. \& Motta, E. (1989). Esperienze in vera grandezza sul comportamento di pali per la stabilizzaaione di un pendio. In Atti del XVII convegno nazionale di geotecnica, vol. 1, pp. 81-90. Rome, Italy: Associazione Geotecnica Italiana (in Italian).

Chen, C. Y. \& Martin, G. R. (2002). Soil-structure interaction for landslide stabilizing piles. Comput. Geotech. 29, No. 5, 363-386, https://doi.org/10.1016/S0266-352X(01)00035-0.

Chen, L. T. \& Poulos, H. G. (1997). Piles subjected to lateral soil movements. J. Geotech. Geoenviron. Engng 123, No. 9, 802-811, https://doi.org/10.1061/(ASCE)1090-0241(1997)123:9(802).

Chow, Y. K. (1996). Analysis of piles used for slope stabilization. Int. J. Numer. Analyt. Methods Geomech. 20, No. 9, 635-646.

Di Laora, R., Maiorano, R. M. S. \& Aversa, S. (2017). Ultimate lateral load of slope-stabilising piles. Géotechnique Lett. 7, No. 3, 237-244, https://doi.org/10.1680/jgele.17.00038.

Durrani, I. K., Ellis, E. A. \& Reddish, D. J. (2008). Numerical modelling of lateral pile-soil interaction for a row of piles in a frictional soil. In Advances in transportation geotechnics (eds E. Ellis, H. S. Yu, G. McDowell, A. Dawson and N. Thom), pp. 291-298, https://doi.org/10.1201/9780203885949. Boca Raton, FL, USA: CRC Press/Balkema.

Ellis, E. A., Durrani, I. K. \& Reddish, D. J. (2010). Numerical modelling of discrete pile rows for slope stability and generic guidance for design. Géotechnique 60, No. 3, 185-195, https://doi.org/10.1680/geot.7.00090.

Esu, F. \& D'Elia, B. (1974). Interazione terreno-struttura in un palo sollecitato dauna frana tipo colata. Riv. Ital. Geotech. 8, No. 1, 27-38 (in Italian).

Gerolymos, N. \& Gazetas, G. (2006). Static and dynamic response of massive caisson foundations with soil and interface nonlinearities - validation and results. Soil Dyn. Earthq. Engng 26, No. 5, 377-394, https://doi.org/10.1016/j.soildyn.2005.12.001.

Gerolymos, N., Zafeirakos, A. \& Karapiperis, K. (2015). Generalized failure envelope for caisson foundations in cohesive soil: static and dynamic loading. Soil Dyn. Earthq. Engng 78, 154-174, https://doi.org/10.1016/j.soildyn.2015.07.012.

Gerolymos, N., Giannakos, S. \& Drosos, V. (2020). Generalised failure envelope for laterally loaded piles: analytical formulation, numerical verification and experimental validation. Géotechnique 70, No. 3, 248-267, https://doi.org/10.1680/jgeot.18.P.051.

Guo, W. D. (2013). Pu-based solutions for slope stabilizing piles. Int. J. Geomech. 13, No. 3, 292-310, https://doi.org/10.1061/ (ASCE)GM.1943-5622.0000201.

Guo, W. D. \& Qin, H. Y. (2010). Thrust and bending moment of rigid piles subjected to moving soil. Can. Geotech. J. 47, No. 2, 180-196, https://doi.org/10.1139/T09-092.

Ito, T. \& Matsui, T. (1975). Methods to estimate lateral force acting on stabilizing piles. Soils Found. 15, No. 4, 43-59, https://doi.org/ 10.3208/sandf1972.15.4 43 .

Kalteziotis, N., Zervogiannis, H., Frank, R., Seve, G. \& Berche, J. C. (1993). Experimental study of landslide stabilization by large diameter piles. In Geotechnical engineering of hard soils-soft rocks: proceedings of an international symposium (ed. A. Anagnostopoulos), pp. 1115-1124. Rotterdam, the Netherlands: Balkema.

Kanagasabai, S., Smethurst, J. A. \& Powrie, W. (2011). Three-dimensional numerical modelling of discrete piles used to stabilize landslides. Can. Geotech. J. 48, No. 9, 1393-1411, https://doi.org/10.1139/t11-046.

Kondner, R. L. (1963). Hyperbolic stress-strain response: cohesive soils. J. Soil Mech. Found. Div. 89, No. 1, 115-143.

Kourkoulis, R., Gelagoti, F., Anastasopoulos, I. \& Gazetas, G. (2011). Slope stabilizing piles and pile-groups: parametric study and design insights. J. Geotech. Geoenviron. Engng 137, No. 7, 663-677, https://doi.org/10.1061/(ASCE)GT.1943-5606.0000479.

Lei, G. \& Wu, W. (2020). Centrifuge study on the effect of pile bending stiffness on the slope stabilised by piles. Int. J. Phys. Model. Geotech. 20, No. 4, 212-223, https://doi. org/10.1680/jphmg.18.00087.

Li, C., Tang, H., Hu, X. \& Wang, L. (2013). Numerical modelling study of the load sharing law of anti-sliding piles based on the soil arching effect for Erliban landslide, China. KSCE J. Civ. Engng 17, No. 6, 1251-1262, https://doi.org/10.1007/ s12205-013-0074-x

Li, C., Wu, J., Tang, H., Hu, X., Liu, X., Wang, C., Liu, T. \& Zhang, Y. (2016a). Model testing of the response of stabilizing piles in landslides with upper hard and lower weak bedrock. Engng Geol. 204, 65-76, https://doi.org/10.1016/j.enggeo.2016. 02.002 .

Li, Z., Kotronis, P., Escoffier, S. \& Tamagnini, C. (2016b). A hypoplastic macroelement for single vertical piles in sand subject to three-dimensional loading conditions. Acta Geotech. 11, No. 2, 373-390, https://doi.org/10.1007/s11440-015-0415-7.

Liang, R. \& Zeng, S. (2002). Numerical study of soil arching mechanism in drilled shafts for slope stabilization. Soils Found. 42, No. 2, 83-92, https://doi.org/10.3208/sandf.42.2_83.

Martin, G. R. \& Chen, C. Y. (2005). Response of piles due to lateral slope movement. Comput. Struct. 83, No. 8-9, 588-598, https://doi.org/10.1016/j.compstruc.2004.11.006.

Page, A. M., Grimstad, G., Eiksund, G. R. \& Jostad, H. P. (2018). A macro-element pile foundation model for integrated analyses of monopile-based offshore wind turbines. Ocean Engng 167, 23-35, https://doi.org/10.1016/j.oceaneng.2018.08.019.

Pan, J. L., Goh, A. T. C., Wong, K. S. \& Teh, C. I. (2002). Ultimate soil pressures for piles subjected to lateral soil movements. J. Geotech. Geoenviron. Engng 128, No. 6, 530-535, https://doi. org/10.1061/(ASCE)1090-0241(2002)128:6(530).

Poulos, H. G. (1971). Behavior of laterally loaded piles: I-single piles. J. Geotech. Engng Div. 97, No. 5, 711-731.

Poulos, H. G. (1973). Analysis of piles in soil undergoing lateral movement. J. Soil Mech. Found. Div. 99, No. 5, 391-406.

Poulos, H. G. (1995). Design of reinforcing piles to increase slope stability. Can. Geotech. J. 32, No. 5, 808-818, https://doi.org/10. 1139/t95-078.

Randolph, M. F. (1981). The response of flexible piles to lateral loading. Géotechnique 31, No. 2, 247-259, https://doi. org/10.1680/geot.1981.31.2.247.

Reese, L. C. \& Van Impe, W. F. (2011). Single piles and pile groups under lateral loading, 2nd edn. Leiden, the Netherlands: CRC Press/Balkema. 
Salciarini, D. \& Tamagnini, C. (2009). A hypoplastic macroelement model for shallow foundations under monotonic and cyclic loads. Acta Geotech. 4, No. 3, 163-176, https://doi.org/10.1007/ s11440-009-0087-2.

Su, D., Huang, J. J. \& Yan, W. M. (2018). Parametric investigation on the responses of laterally loaded piles in overconsolidated clay using nondimensional solutions addressing nonlinear soil-pile interaction. Comput. Geotech. 96, 203-214, https:// doi.org/10.1016/j.compgeo.2017.11.004.

Tang, H., Hu, X., Xu, C., Li, C., Yong, R. \& Wang, L. (2014). A novel approach for determining landslide pushing force based on landslide-pile interactions. Engng Geol. 182, 15-24, https://doi.org/10.1016/j.enggeo.2014.07.024.

Viggiani, C. (1981). Ultimate lateral load on piles used to stabilize landslides. In Proceedings of 10th international conference on soil mechanics and foundation engineering (ed. Publications
Committee of X ICSMFE), pp. 555-560. Rotterdam, the Netherlands: A.A. Balkema.

White, D. J., Thompson, M. J., Suleiman, M. T. \& Schaefer, V. R. (2008). Behavior of slender piles subject to free-field lateral soil movement. J. Geotech. Geoenviron. Engng 134, No. 4, 428-436.

Yoon, B. S. \& Ellis, E. A. (2009). Centrifuge modelling of slope stabilisation using a discrete pile row. Geomech. Geoengng 4, No. 2, 103-108, https://doi.org/10.1080/17486020902856991.

Zafeirakos, A. \& Gerolymos, N. (2013). On the seismic response of under-designed caisson foundations. Bull. Earthq. Engng 11, No. 5, 1337-1372, https://doi.org/10.1007/s10518-013-9465-0.

Zhang, L. \& Ahmari, S. (2013). Nonlinear analysis of laterally loaded rigid piles in cohesive soil. Int. J. Numer. Analyt. Methods Geomech. 37, No. 2, 201-220, https://doi.org/10.1002/ nag.1094. 